Research Article

\title{
Characteristics of Raindrop Size Distribution in Typhoon Nida (2016) before and after Landfall in Southern China from 2D Video Disdrometer Data
}

\author{
Lu Feng, ${ }^{1}$ Xiantong Liu, ${ }^{1}$ Hui Xiao $\mathbb{D}^{1},{ }^{1}$ Liusi Xiao, ${ }^{2}$ Feng Xia, ${ }^{1}$ Xiao Hao, ${ }^{2}$ Haiqi Lu, ${ }^{3}$ \\ and Chenxian Zhang ${ }^{4}$ \\ ${ }^{1}$ Guangzhou Institute of Tropical and Marine Meteorology, China Meteorological Administration, Guangzhou 510641, China \\ ${ }^{2}$ Guangzhou Meteorological Observatory, China Meteorological Administration, Guangzhou 511430, China \\ ${ }^{3}$ Jieyang Meteorological Bureau, China Meteorological Administration, Jieyang, Guangdong 515500, China \\ ${ }^{4}$ Qingyuan Meteorological Observatory, China Meteorological Administration, Qingyuan, Guangdong 511518, China
}

Correspondence should be addressed to Hui Xiao; xiaoh@gd121.cn

Received 25 May 2021; Accepted 2 August 2021; Published 12 August 2021

Academic Editor: Roberto Fraile

Copyright (C) $2021 \mathrm{Lu}$ Feng et al. This is an open access article distributed under the Creative Commons Attribution License, which permits unrestricted use, distribution, and reproduction in any medium, provided the original work is properly cited.

During the passage of Typhoon Nida, the raindrop size distribution parameters, the raindrop spectra, the shape and slope $(\mu-\Lambda)$ relationship, the radar reflectivity factor, and rain rate $(Z-R)$ relationship were investigated based on a two-dimensional (2D) video disdrometer in Guangdong, China, from August 1 to 2, 2016. Due to the underlying surface difference between the ocean and land, this process was divided into two distinct periods (before landfall and after landfall). The characteristics of raindrop size distribution between the period before landfall and the period after landfall were quite distinct. The period after landfall exhibited higher concentrations of each size bin (particularly small drops) and wider raindrop spectral width than the period before landfall. Compared with the period before landfall, the period after landfall had a higher average mass-weighted mean diameter $D_{m}$ that was smaller than those of other TCs from the same ocean (the Pacific). The $\mu-\Lambda$ relationship and $Z-R$ relationship in this study were also compared with other TCs from the same ocean (the Pacific). This investigation of the microphysical characteristics of Typhoon Nida before landfall and after landfall may improve radar quantitative precipitation estimation (QPE) products and microphysical schemes by providing useful information.

\section{Introduction}

Tropical cyclones (TCs) usually bring heavy precipitation, strong winds, lightning strikes, and storm surge, which cause economic loss and endanger human security. Southern China is the most TC-prone area within China. An average of two to three TCs make landfall in southern China each year. This indicates the necessity of investigating TC precipitation characteristics in southern China to improve TC precipitation forecasts.

Raindrop size distribution (DSD) is essential for meteorological fields, such as in numerical weather prediction models $[1,2]$. Under different microphysical and dynamic processes, the DSD expresses different characteristics [3].
Thus, the DSD varies with different rain types, climate regions, and weather systems [4-7].

With the development of technology, an increasing number of instruments are being used to measure DSD parameters. In situ disdrometer devices, such as the laser disdrometer like OTT Parsivel and the 2D video disdrometer (2DVD), are now used extensively. The DSD characteristics of precipitation systems have been investigated using in situ disdrometers [8-12]. Raupach and Berne [13] indicated that methods using the DSD parameters measured by a Parsivel disdrometer should be corrected using a 2DVD as a reference instrument. Kruger and Krajewski [14] and Liu et al. [15] compared 2DVD with the Parsivel disdrometer and found that because of the orthogonality of scanning, 2DVD 
can effectually prevent particle superposition errors. Adirosi et al. [16] evaluated the Micro Rain Radar (MRR) performance for rainfall and DSD parameters, considering 2DVD as a primary reference.

Moreover, remote sensing instruments, such as polarization radar and satellites, are widely used to obtain a wide range of DSDs [17-21]. Zhang and $\mathrm{Fu}$ [22] examined the microphysical processes in raindrops during each stage in the life cycle of clouds by satellite (Global Precipitation Measurement (GPM) mission). Chen et al. [23] revealed the relationship between droplet growth modes and cloud particle microphysics using FY-4A satellite and GPM DPR data.

Previous studies have revealed that TCs feature higher concentrations of small and midsize drops, compared with non-TCs [24-27]. Radhakrishna and Rao [27] found that large drops in cyclonic rain were negligible, and few small to midsize drops were present in non-TC rain, possibly due to a large amount of evaporation. Deo and Walsh [28] also implied that the DSDs of TCs varied with distance from the TC center.

In addition, the DSDs of TCs vary with different rain region and rain type, which is associated with different rain formation in terms of dynamic and thermodynamic mechanisms $[29,30]$. TCs from different oceans were examined by Janapati et al. [31]. This study indicated that the $Z-R$ relationship in the Indian Ocean was distinctly different from that in the Pacific. Wen et al. [25] analyzed the DSDs of TCs making landfall in China. They found that when $\Lambda$ was given, the value of $\mu$ was lower than those typhoons making landfall in the western Pacific, which were studied by Chang et al. [26]. Chang et al. [26] focused on different rain types and implied that the DSDs of TCs over the ocean were mainly maritime-like convection, while those over land fell between continental-like and maritime-like convection, as defined by Bringi et al. [4]. Other studies [31-35] focused on the differences in the DSD characteristics of the inner core (eyewall) and outer rainbands. Feng et al. [33] found that the concentrations of each size bin in the inner core were higher than those in the outer rainbands.

Even though many scientists have investigated the DSDs of TC systems, there have been few documented studies in southern China and still fewer focusing on the difference between DSDs before landfall and after landfall over southern China. Therefore, on the basis of microphysical information provided by $2 \mathrm{DVD}$, this study reported the differences between DSD characteristics in Typhoon Nida before landfall and after landfall in southern China.

\section{Data and Methodology}

2.1. 2D Video Disdrometer. The 2D Video Disdrometer (2DVD) is the third-version disdrometer manufactured by Joanneum Research in Graz, Austria, which performs the orthogonality of scanning $(55 \mathrm{kHz})$ and measures the particle sizes (0.1-8.1 mm). The website (https://www. distrometer.at) provides details about the 2DVD. In this study, the temporal resolution of this data was preprocessed into 1 minute and then adopted using the quality control method of Tokay [36] to minimize the measurement errors. The processed 2DVD data have been assessed with rain gauge data by Feng et al. [37]. During Typhoon Nida's passage over Guangdong Province on August 1-2, 2016, the Longmen Field Experiment Base for Cloud Physics of the China Meteorological Administration in Guangdong, China, at the Longmen site $\left(23.781^{\circ} \mathrm{N}, 114.248^{\circ} \mathrm{E}\right)$ obtained the observation of $2 \mathrm{DVD}$.

The raindrop concentration $\left(N\left(D_{i}\right)\right)$ from 2DVD is calculated as follows:

$$
N\left(D_{i}\right)=\frac{1}{\Delta t \Delta D_{i}} \sum_{j=1}^{n(i)} \frac{1}{A \cdot V_{j}} .
$$

where $D_{i}(\mathrm{~mm})$ represents the raindrop diameter for the $i^{\text {th }}$ size bin; $\Delta D_{i}(\mathrm{~mm})$ represents the interval of diameter $(0.2 \mathrm{~mm}) ; n(i)$ represents the number of drops for the $i^{\text {th }}$ size bin; $V_{j}\left(\mathrm{~m} \mathrm{~s}^{-1}\right)$ represents the fall speed for the $j^{t h}$ size bin drops; $A$ represents the sampling area $\left(10 \times 10 \mathrm{~cm}^{2}\right)$; and $\Delta t$ represents the sampling time (60s).

If $N\left(D_{i}\right)$ is given, the parameters such as rainfall rate $R$ $\left(\mathrm{mm} \mathrm{h}^{-1}\right)$, radar reflectivity $Z\left(\mathrm{~mm}^{6} \mathrm{~m}^{-3}\right)$, liquid water content LWC $\left(\mathrm{g} \mathrm{m}^{-3}\right)$, and the total raindrop number concentration $N_{t}\left(\mathrm{~m}^{-3}\right)$ can be calculated as follows:

$$
\begin{aligned}
R & =\frac{6 \pi}{10^{4}} \sum_{i=1}^{L} D_{i}^{3} V_{i} N\left(D_{i}\right) \Delta D_{i}, \\
Z & =\sum_{i=1}^{L} D_{i}^{6} N\left(D_{i}\right) \Delta D_{i}, \\
\mathrm{LWC} & =\frac{\pi}{6000} \sum_{i=1}^{L} D_{i}^{3} N\left(D_{i}\right) \Delta D_{i}, \\
N_{t} & =\sum_{i=1}^{L} N\left(D_{i}\right) \Delta D_{i} .
\end{aligned}
$$

The DSD expression for the $n^{\text {th }}$ order moment is defined as follows:

$$
M_{n}=\int_{0}^{D_{\max }} N(D) D^{n} \mathrm{~d} D
$$

The mass-weighted mean diameter $D_{m}(\mathrm{~mm})$ can be calculated as follows:

$$
D_{m}=\frac{M_{4}}{M_{3}},
$$

where $L$ represents the total number of bins (41) and $M_{4}$ and $M_{3}$ represent the DSD for the fourth and third moments, respectively.

The expression of standardized intercept parameter $N_{w}$ $\left(\mathrm{mm}^{-1} \mathrm{~m}^{-3}\right)$ can be calculated as follows:

$$
N_{w}=\frac{(4.0)^{4}}{\pi \rho_{\omega}}\left(\frac{10^{3} W}{D_{m}^{4}}\right),
$$

where $\rho_{\omega}\left(10^{6} \mathrm{~g} \mathrm{~m}^{-3}\right)$ represents the water density and $W\left(\mathrm{~g} \mathrm{~m}^{-3}\right)$ represents the rainwater content. 
2.2. S-Band Polarimetric Radar. The Guangzhou S-band polarimetric radar $\left(22.962^{\circ} \mathrm{N}, 113.363^{\circ} \mathrm{E}\right)$ belongs to Guangzhou Meteorological Bureau, China Meteorological Administration, which has been upgraded from CINRAD/ SA radar. Based on the dual-polarization/double-emission and double-receiving model, the S-band polarimetric radar can achieve double-polarization parameters, which reflect the size, density, and deformation of precipitation particles in the precipitation cloud system. The S-band polarimetric radar has a resolution range of 1000 to $250 \mathrm{~m}$, an elevation angle of $0.5^{\circ}$ to $6.0^{\circ}$, and a temporal resolution of $6 \mathrm{~min}$. In this study, the S-band polarimetric radar data have been adopted by the quality control method of Liu et al. [15] for system noise and hardware issues.

\section{Results}

3.1. Overview of Typhoon Nida. In the summer of 2016, Typhoon Nida caused heavy rainfall and losses to the economy of southern China because it lasted for an extended period of time and grew rapidly. Moreover, due to Typhoon Nida, 1 person died and at least 12 people in southern China were injured. For Typhoon Nida, Wu et al. [38] and Feng et al. [39] focused on the microphysical convective cells in an outer rainband and the effect of drag coefficient parameterizations on air-sea coupled simulations, respectively. In this study, the environmental condition and microphysical characteristics from the period before landfall to the period after landfall have been analyzed.

Typhoon Nida (initially classified as a tropical storm) formed over the ocean east of the Philippines at 17:00 Beijing Standard Time (BST) on July 30, 2016, and then moved to the northwest (Figure 1(a)). At 03:35 BST on August 2, 2016, Typhoon Nida (the grade of strong typhoon) made landfall in Shenzhen, Guangdong Province. The intensity of Typhoon Nida then diminished, with its grade dropping from typhoon to tropical depression, and it finally dissipated at 08 : 00 BST on August 3, 2016. The maximum wind speeds (central pressure) of Typhoon Nida increased (decreased) steadily and then decreased (increased) rapidly (Figure 1(b)). When Typhoon Nida crossed over the coastal area (around 03:00 BST), the maximum wind speed reached its peak $\left(42 \mathrm{~m} \mathrm{~s}^{-1}\right)$, while the central pressure reached its minimum $(960 \mathrm{hPa})$. The National Meteorological Center (https://typhoon.nmc.cn/web.html) provided the observed track of the TC and the standard used to distinguish different grades of TC based on the maximum average wind speed of the TC center in the surface layer. According to the definition proposed by Janapati et al. [34], the time of landfall is the time when the center of the TC first lands in the coastal area. Additionally, in this study, the rain rate at a given location was considered to be influenced by the TC when the distance between that location and the TC center was $<500 \mathrm{~km}[28,31,40]$. Thus, for Longmen, the period before landfall is from 17:00 BST August 1, 2016, to 03:35 BST August 2, 2016, and that after landfall is from 03:35 BST August 2, 2016, to 18:00 BST August 2, 2016. During the period before landfall (Figure 1(c)), Longmen was in the right front quadrant of the outer rainbands. Then during the period after landfall (Figure 1(d)), Typhoon Nida continued moving northwest; Longmen was in the rear side of the outer rainbands.

The reanalysis data of the National Centers for Environmental Prediction's (NECP) were used to analyze the source of water vapors. Figure 2 shows the periods before landfall and after landfall, which indicated that the moisture flux divergence from the Bay of Bengal and the South China Sea provided a sea of moisture to Typhoon Nida. From 08:00 to 14:00 BST August 1, 2016 (Figures 2(a) and 2(b)), there was no water vapor at Longmen. Subsequently, the moisture flux divergence moved northwest and strengthened. At 20:00 BST on August 1, 2016 (Figure 2(c)), a small amount of moisture began to occur in Longmen. From 02:00 to 08:00 BST on August 2, 2016 (Figures 2(d) and 2(e)), the moisture flux divergence at Longmen enhanced rapidly and reached more than $50 \mathrm{~g} \mathrm{~cm}^{-1} \mathrm{hPa}^{-1} \mathrm{~s}^{-1}$. Finally, Longmen still maintained sufficient vapors with the moisture flux divergence about $25 \mathrm{~g} \mathrm{~cm}^{-1} \mathrm{hPa}^{-1} \mathrm{~s}^{-1}$ at 14:00 (Figure 2(f)). In brief, a larger duration and intensity of the moisture flux divergence at Longmen were found after landfall than before rainfall.

Next, we examined the sounding at Heyuan station around Longmen, which was used to analyze atmospheric stratification. Heyuan station $\left(114.733^{\circ} \mathrm{E}, 23.804^{\circ} \mathrm{N}\right)$ is located $50 \mathrm{~km}$ to the northeast of Longmen. At 20:00 BST on July 31, 2016 (Figure 3(a)), before the approach of Typhoon Nida, it was dry below $300 \mathrm{hPa}$ with a convective available potential energy (CAPE) value of $3434 \mathrm{~J} \mathrm{~kg}^{-1}$, the lifting condensation level (LCL) value of $880 \mathrm{hPa}$, and the total precipitable water (TPW) value of $50 \mathrm{~mm}$. Then at 08:00 BST on August 1, 2016 (Figure 3(b)), it showed unstable statues with a "horn-type" sounding that it was dry above $700 \mathrm{hPa}$, relatively wet below $700 \mathrm{hPa}$, and a CAPE value of $932 \mathrm{~J} \mathrm{~kg}^{-1}$ (the blue line and black line form a horn shape in Figure 3(b)). This indicated that thunderstorms and hail seemed to happen at Heyuan station. Then at 20:00 BST (Figure 3(c)), the dew-point temperature profile of air was close to the temperature profile of air above $500 \mathrm{hPa}$. After 12 hours (Figure 3(d)), the dew-point temperature profile of air was close to the temperature profile of air at each layer of atmosphere, and the value of CAPE was very low $\left(6 \mathrm{~J} \mathrm{~kg}^{-1}\right)$, and the value of TPW was very large $(70 \mathrm{~mm})$. This indicated that after landfall, the warm and moist air in the surface layer mainly resulted in the development of an unstable status of the atmosphere. Moreover, compared with the period before landfall, the period after landfall had a deep wet layer, which was in accord with the result of Figure 2. The freezing level was about $5.2 \mathrm{~km}$ (Figure $3(\mathrm{~d})$ ).

Furthermore, to gain a better understanding of the vertical microphysical structures of typhoon precipitation, we examined the occurrence frequency and averaged profiles of radar reflectivity $\left(Z_{H}\right)$, differential reflectivity $\left(Z_{\mathrm{DR}}\right)$, and the differential specific $\left(K_{\mathrm{DP}}\right)$ in the vertical direction before landfall and after landfall (Figure 4). During the period before landfall, below the freezing level $\left(0^{\circ} \mathrm{C}\right)$, the $Z_{H}$ was mainly between 10 and $25 \mathrm{dBZ}$ (Figure $4(\mathrm{a})$ ) and the $Z_{\mathrm{DR}}$ was mainly between 0 and $0.5 \mathrm{~dB}$ (Figure $4(\mathrm{a})$ ). Above the freezing level, the $Z_{H}$ decreasing with the increasing altitude 


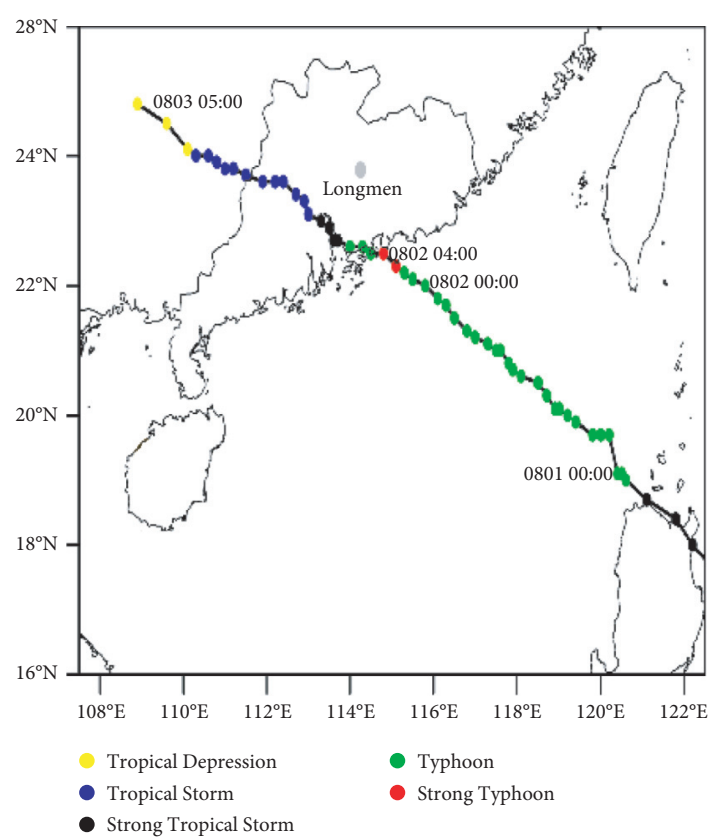

(a)

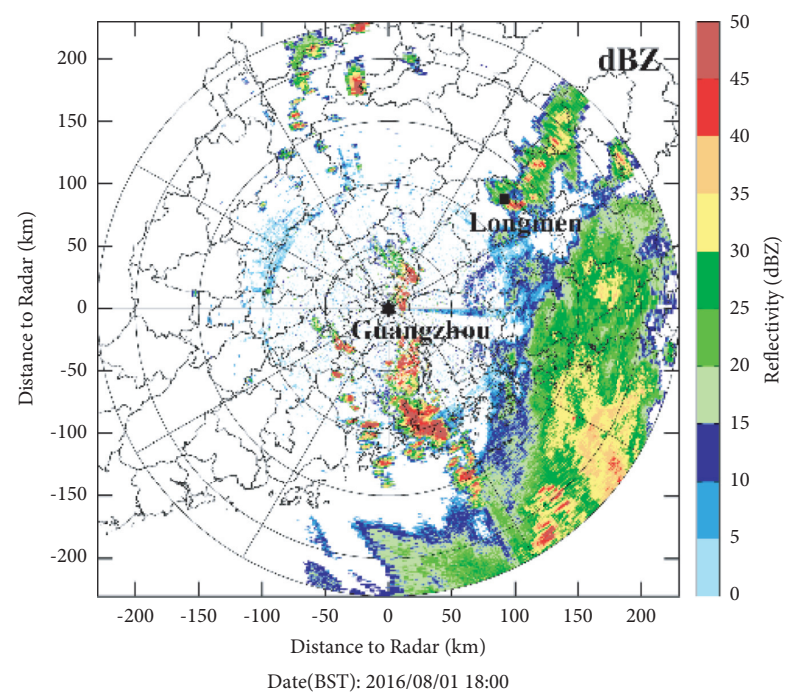

(c)

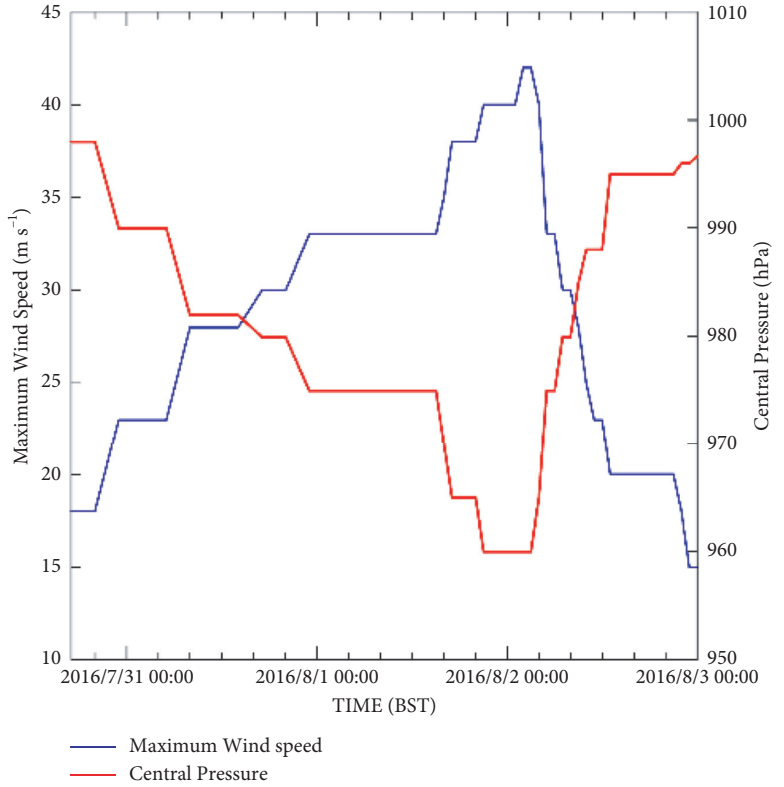

(b)

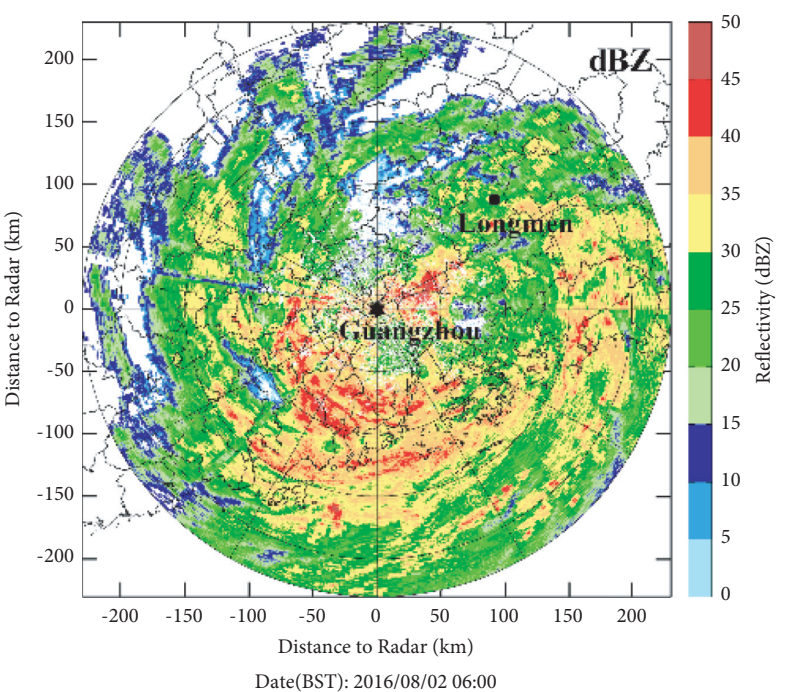

(d)

Figure 1: Observed track every $3 \mathrm{~h}$ from 14:00 BST July 30, 2016, to 05:00 BST August 3, 2016. The colored dots represent different grades of TC (a). Time evolutions of maximum wind speed $\left(\mathrm{m} \mathrm{s}^{-1}\right)$ and central pressure (hPa) of Typhoon Nida (b). Radar reflectivity $Z$ (dBZ) observed from Guangzhou S-band polarimetric radar at 18:00 BST on August 1 (c) and at 06:00 BST on August 2, 2016 (d).

indicated that the supercooled water or large frozen hydrometeors were finite $[19,25]$. The $K_{\mathrm{DP}}$ of the whole layer was concentrated around $0 \% \mathrm{~km}$, which indicated that the water content of the cloud was low. Then during the period after landfall, below the freezing level, the $Z_{H}, Z_{\mathrm{DR}}$, and $K_{\mathrm{DP}}$ were higher than those before landfall (Figure 4(d)). This indicated that, compared with the period before landfall, the period after landfall had a high concentration of rain particles and raindrop size. Around the level of $-10^{\circ} \mathrm{C}$, compared with the period before landfall, the period after landfall had a similar value of $Z_{\mathrm{DR}}$ and high value of $K_{\mathrm{DP}}$, which indicated a uniform raindrop size and a higher concentration of raindrop.
3.2. Characteristics of Raindrop Size Distribution. In this study, we defined small drops (diameter $<1 \mathrm{~mm}$ ), midsize drops (diameter between 1 and $3 \mathrm{~mm}$ ), and large drops (diameter $>$ $3 \mathrm{~mm}$ ) following definitions given by Tokay et al. [36]. During the period before landfall, there was persistent precipitation from 01:00 to 03:35 BST with a peak rain rate of $29 \mathrm{~mm} \mathrm{~h}^{-1}$, a maximum raindrop diameter of $3.5 \mathrm{~mm}$, and a small drop concentration of $<4.3 \mathrm{~mm}^{-1} \mathrm{~m}^{-3}$ (Figure 5(a)). During the period after landfall, there was persistent heavy precipitation and the distance of the center of Typhoon Nida from the Longmen was $<150 \mathrm{~km}$ from 04:00 to 12:00 BST August 2, 2016. In addition, the maximum rain rate $\left(63 \mathrm{~mm} \mathrm{~h}^{-1}\right)$ occurred at 07 : 30 BST on August 2, 2016, with a maximum raindrop diameter 


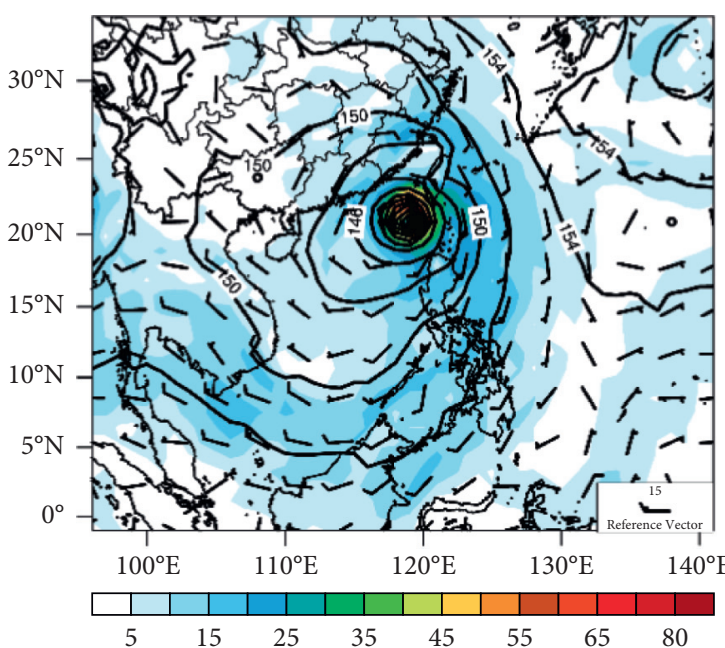

(a)

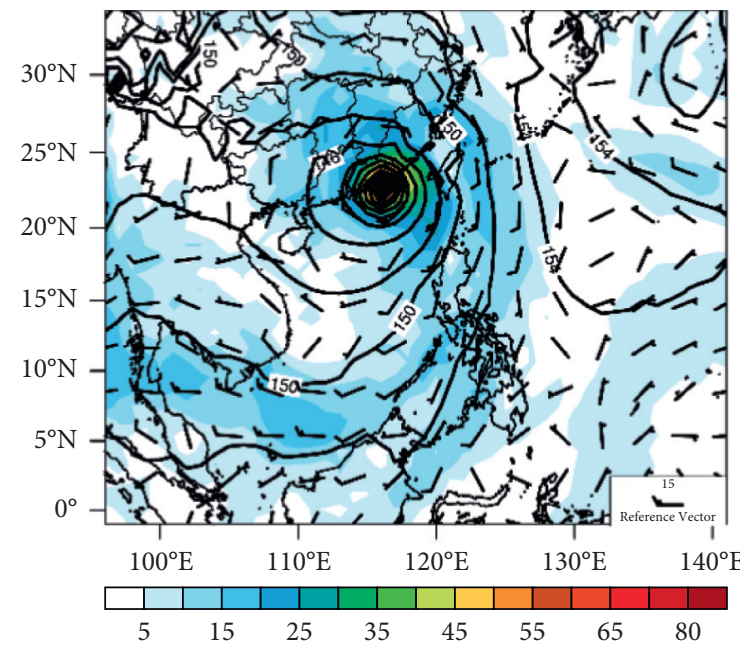

(c)

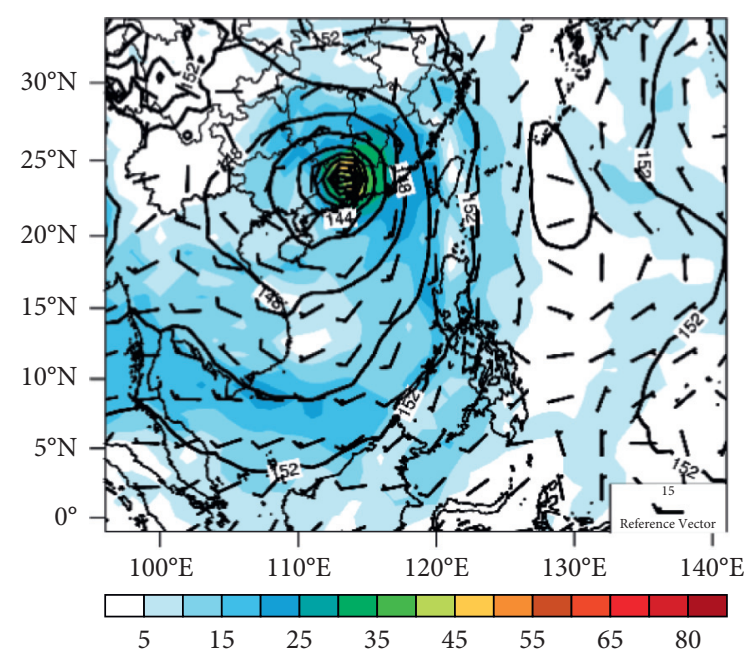

(e)

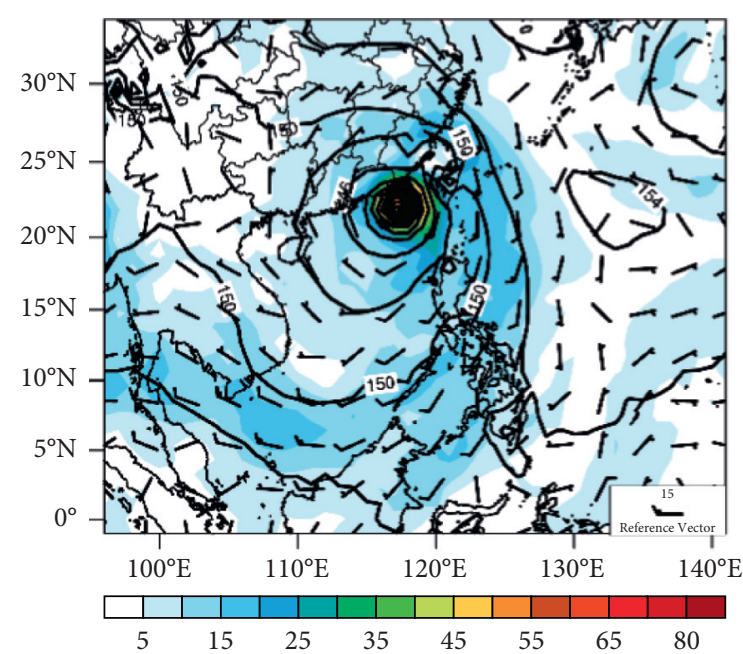

(b)

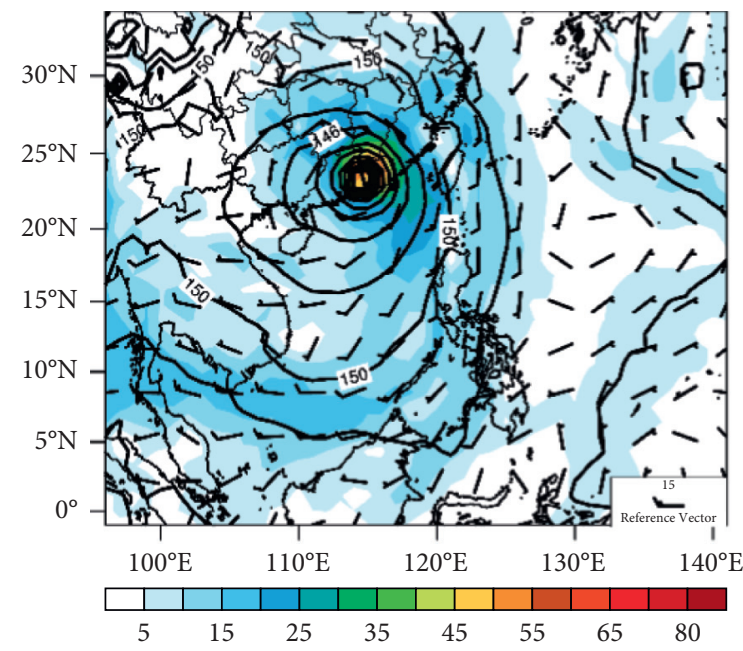

(d)

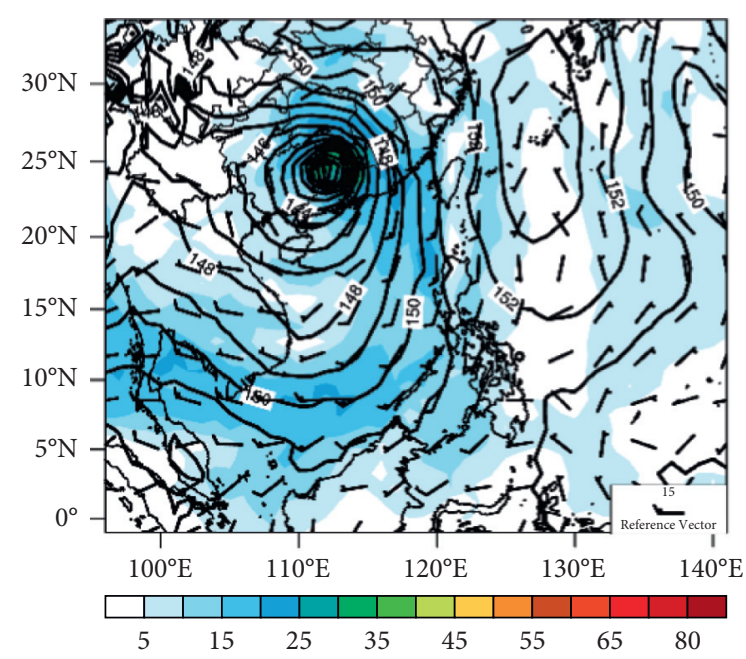

(f)

FIGURe 2: Wind field $\left(\mathrm{m} \mathrm{s}^{-1}\right)$ and moisture flux divergence $\left(\mathrm{g} \mathrm{cm}^{-1} \mathrm{hPa}^{-1} \mathrm{~s}^{-1}\right)$ at $850 \mathrm{hPa}$ every $6 \mathrm{~h}$ from 08:00 BST on August 1 to 14:00 BST on August 2, 2016. (a) 2016/08/01 08:00 BST; (b) 2016/08/01 14:00 BST; (c) 2016/08/01 20:00 BST; (d) 2016/08/02 20:00 BST; (e) 2016/08/02 08:00 BST; (f) 2016/08/02 14:00 BST. 


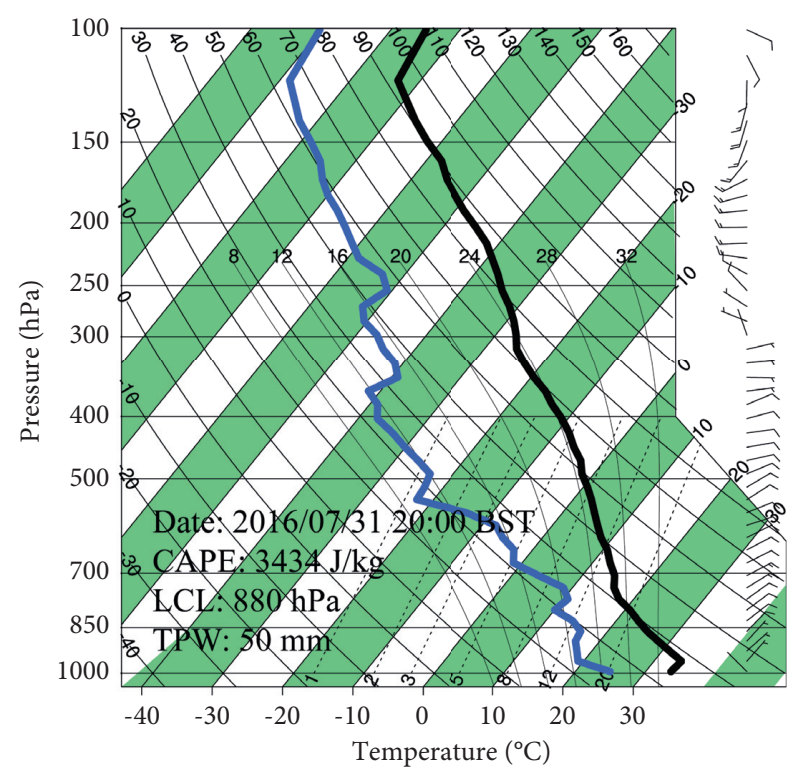

(a)

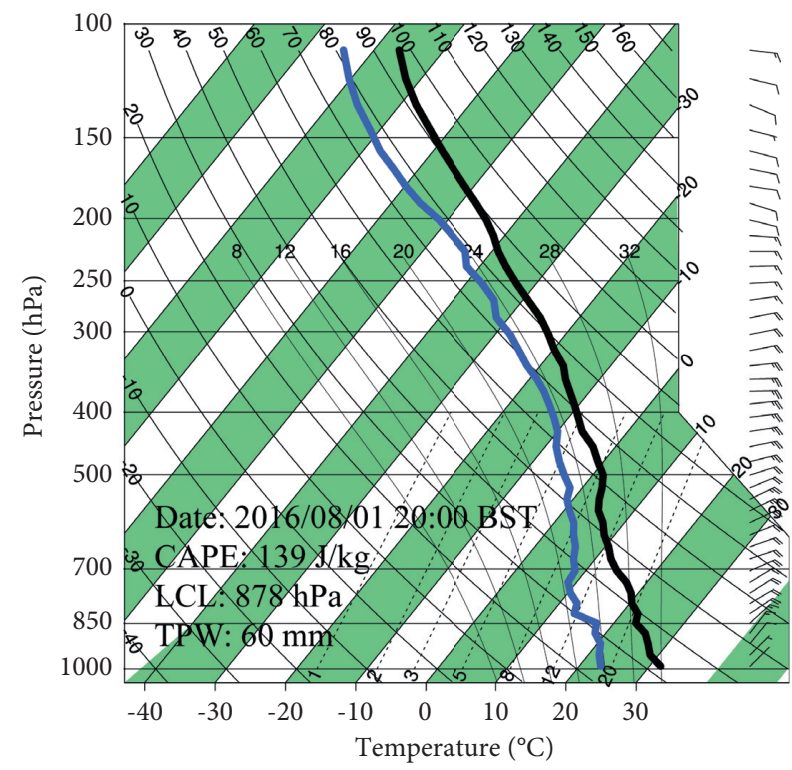

(c)

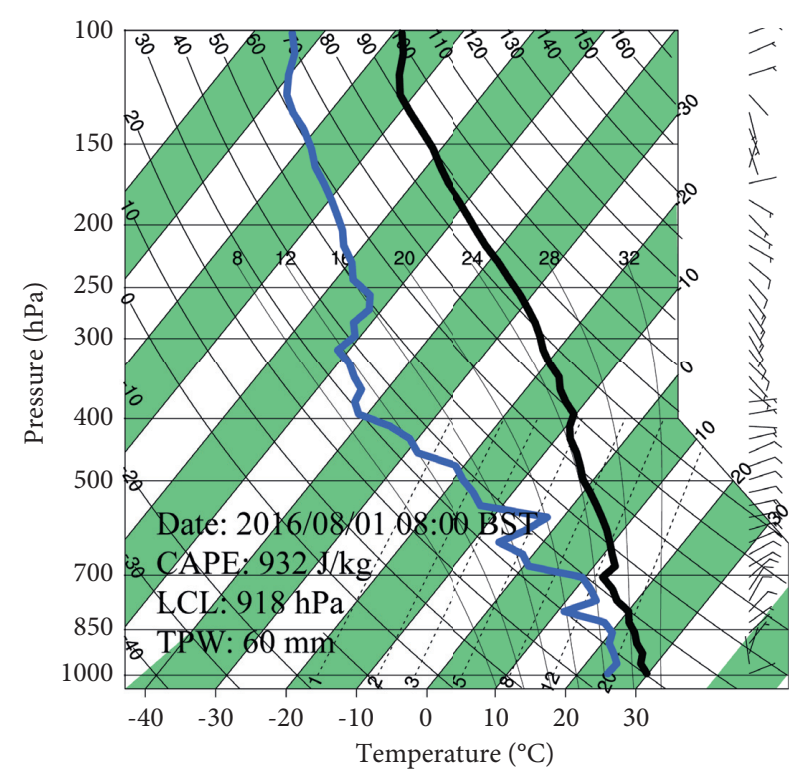

(b)

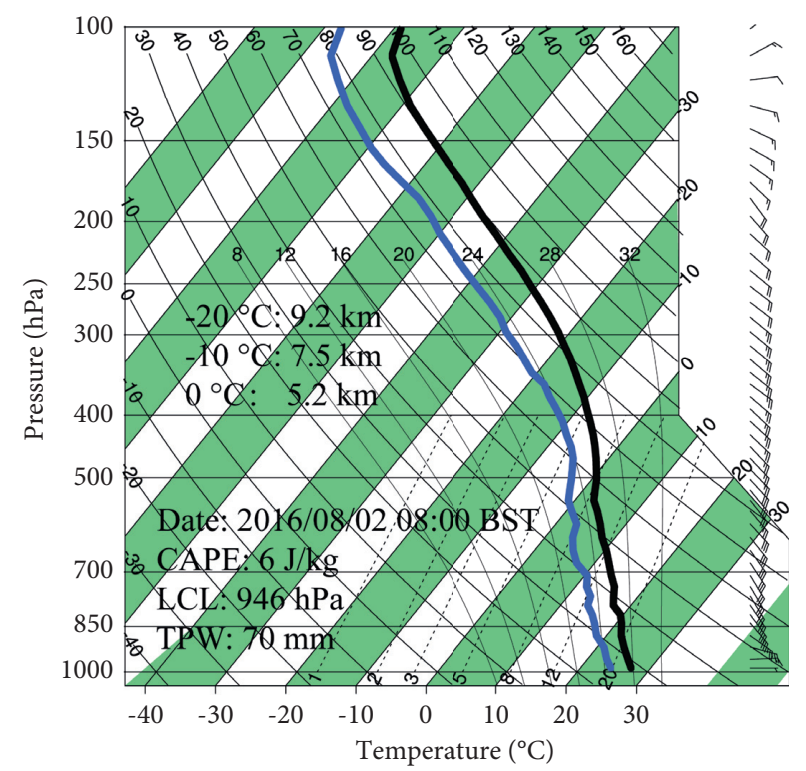

(d)

FIgURE 3: Sounding from Heyuan station every $12 \mathrm{~h}$ from 20:00 BST July 31, 2016, to 08:00 BST August 2, 2016.

of $4.3 \mathrm{~mm}$, and a small drop concentration of $4.7 \mathrm{~mm}^{-1} \mathrm{~m}^{-3}$. After this period, there was persistent precipitation from 11:30 to 18:00 BST on August 2, 2016, with increasing distance from the center, while rain rate exhibited several peak values, and the concentration of small drops and the maximum drop diameter increased first and then decreased.

The DSD parameters before landfall and after landfall are presented in Figure 6. Compared with the period before landfall, the maximum raindrop diameter was $4.3 \mathrm{~mm}$, the raindrop spectra were wider, and the number of concentration was high within each size bin in the period after landfall (Figure 6(a)), which was in accord with the result of Figure 4. From the period before landfall to that after landfall, the mean values of $D_{m}$ and $N_{w}$ increased (Figure 6(b)). Previous studies
$[25,31]$ have demonstrated that the DSDs of different TCs are distinct. Hence, we compared the $D_{m}-N_{w}$ pairs with those of other TCs from the same ocean (the Pacific) (Figure 6(b)). Our $D_{m}$ was smaller than the results of Bao et al. [41], Janapati et al. [31], and Zheng et al. [42], while our $N_{w}$ was smaller than two of the results. This is probably because the results have higher rain rates and higher concentration of large drops than Typhoon Nida in this study. The shape and slope $(\mu-\lambda)$ relationship was described with quadratic polynomial with one variable, and the period before landfall and the period after landfall had broadly similar coefficients (Figure 6(c)). This indicated that the shape and slope of Gamma raindrop size distribution were similar before landfall and after landfall, which was in accord with Figure 6(a). However, the $\mu-\lambda$ 
Before landfall

(a1)

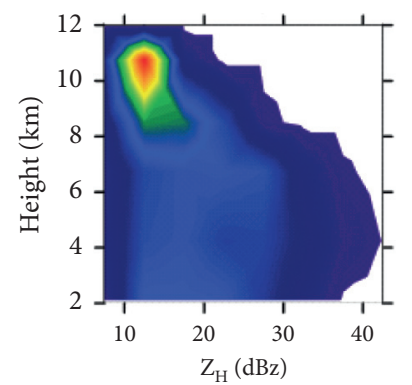

(a2)

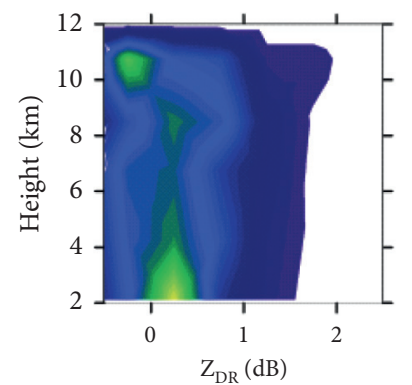

(a3)

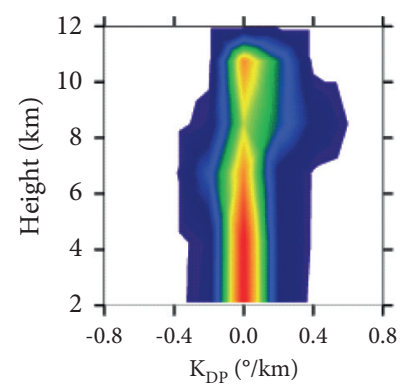

$\%$

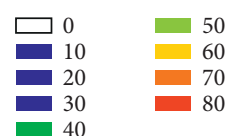

After landfall

(b1)

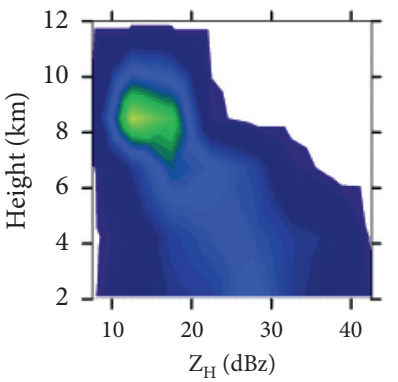

(b2)

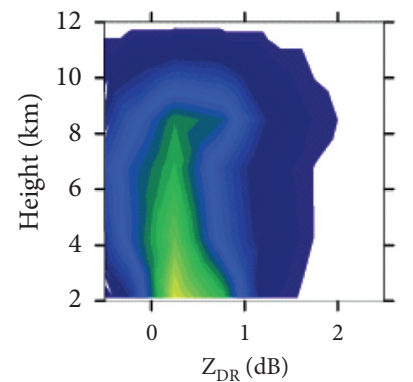

(b3)

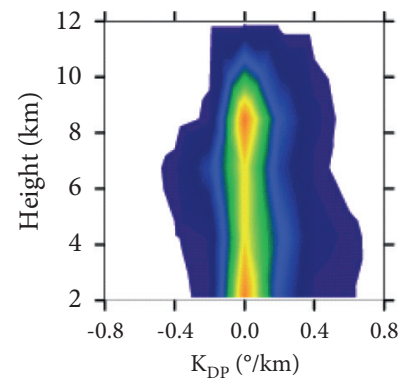

$\%$

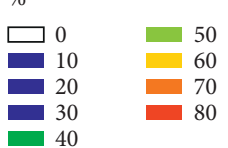

After-Before

(c1)

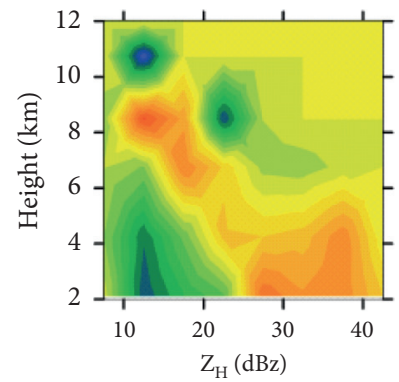

(c2)

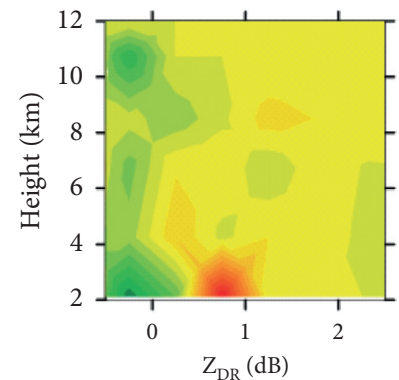

(c3)
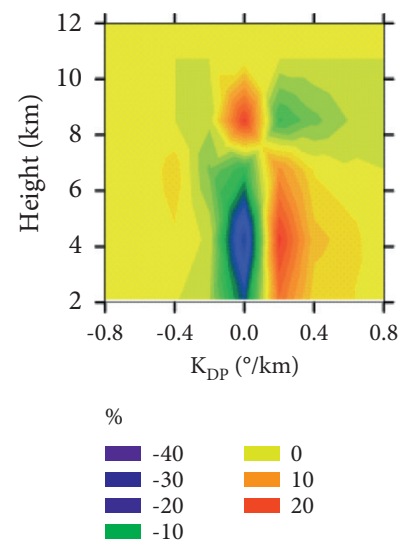

Mean

(d1)

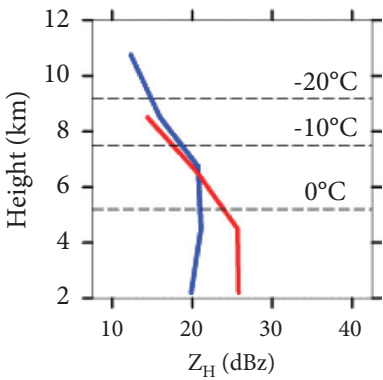

(d2)

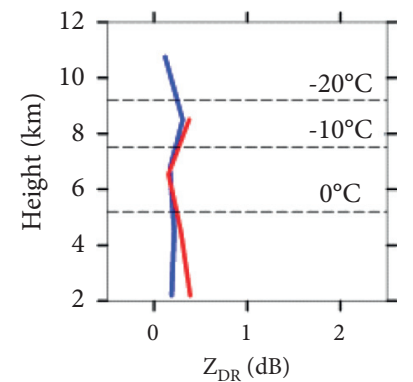

(d3)

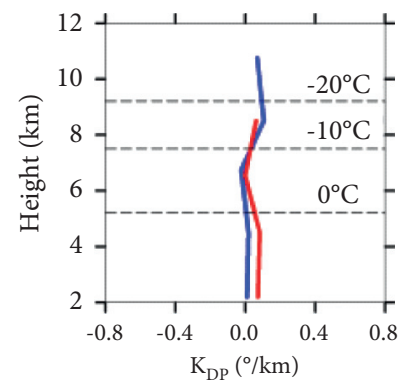

- Before

Figure 4: The occurrence frequency (\%) before landfall (a) and after landfall (b), the difference between these two segments (c), and vertical profiles (d) of radar reflectivity $Z_{H}(\mathrm{dBZ})$, differential reflectivity $Z_{\mathrm{DR}}(\mathrm{dB})$, and specific differential phase $K_{\mathrm{DP}}\left({ }^{\circ} / \mathrm{km}\right)$. Three black dotted lines represent the level of $0^{\circ} \mathrm{C},-10^{\circ} \mathrm{C}$, and $-20^{\circ} \mathrm{C}$, respectively.

relationship in this study is different from those of other TCs from the same ocean (the Pacific), which is consistent with the result of Zhang et al. [43] that the $\mu-\lambda$ relationships in different regions or different rain types are distinct due to different microphysical process and formation mechanism. Previous studies [44-47] have investigated that the relationship between radar factor and rain rate $(Z-R)$ is expressed by the form of $Z=A * R^{b}$, where $A$ and $b$ vary with the raindrop size distribution and spatial scale. Appropriate coefficients ( $A$ and $b$ ) can improve the precision of local precipitation estimation. Compared with the period before landfall, the period after landfall had a small value of $A$ and a large value of $b$ (Figure $6(\mathrm{~d})$ ). The $Z-R$ relationship is significantly distinct between before landfall and after landfall. Moreover, the $Z-R$ relationship in this study is different from the results of Bao et al. [41] and Janapati et al. [31]. Moreover, the mean values of the above parameters $\left(R, Z, D_{m}\right.$, and $\left.\lg N_{w}\right)$ before and after landfall are listed in Table 1.

To make it clear, we also examined the DSD characteristics of different rain rate $\left(\mathrm{mm} \mathrm{h}^{-1}\right)$ classes (first class: $0.1-1 \mathrm{~mm} \mathrm{~h}^{-1}$, second class: $1-5 \mathrm{~mm} \mathrm{~h}^{-1}$, third class: $5-10 \mathrm{~mm} \mathrm{~h}^{-1}$, fourth class: 10-20 $\mathrm{mm} \mathrm{h}^{-1}$, fifth class: $20-30 \mathrm{~mm} \mathrm{~h}^{-1}$, sixth class: $30-40 \mathrm{~mm}$ $\mathrm{h}^{-1}$, seventh class: $40-50 \mathrm{~mm} \mathrm{~h}^{-1}$, and eighth class: $>50 \mathrm{~mm}$ $\mathrm{h}^{-1}$ ) before landfall and after landfall. The precipitation particles mainly consist of the drops of $R<10 \mathrm{~mm} \mathrm{~h}^{-1}$ before landfall and the drops of $R<20 \mathrm{~mm} \mathrm{~h}^{-1}$ after landfall (Table 1). 

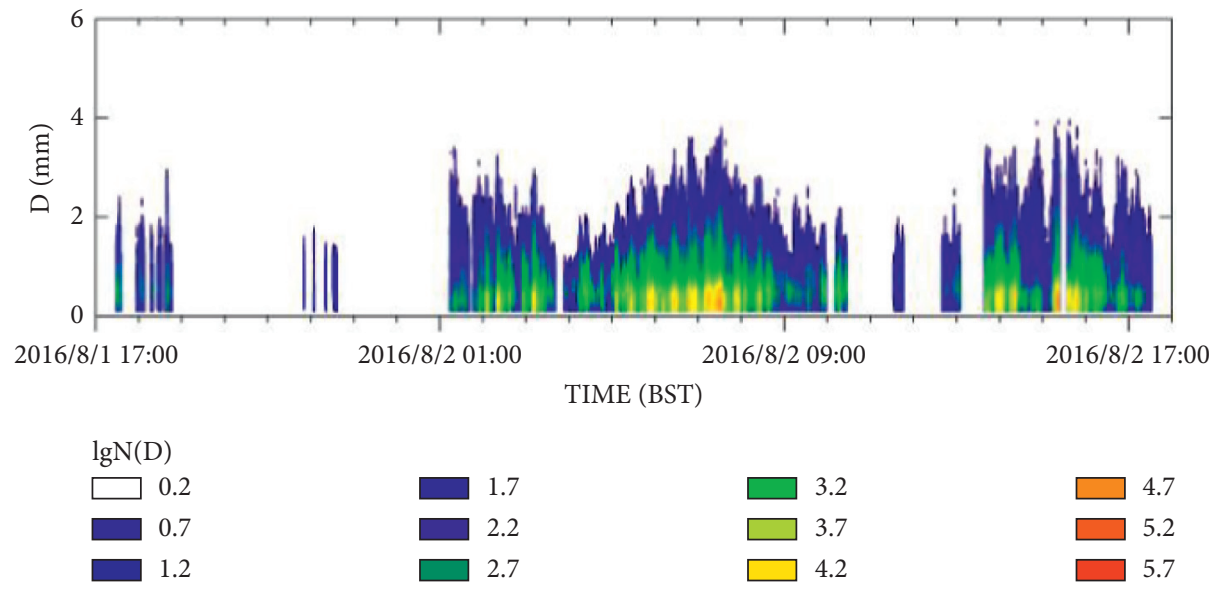

(a)

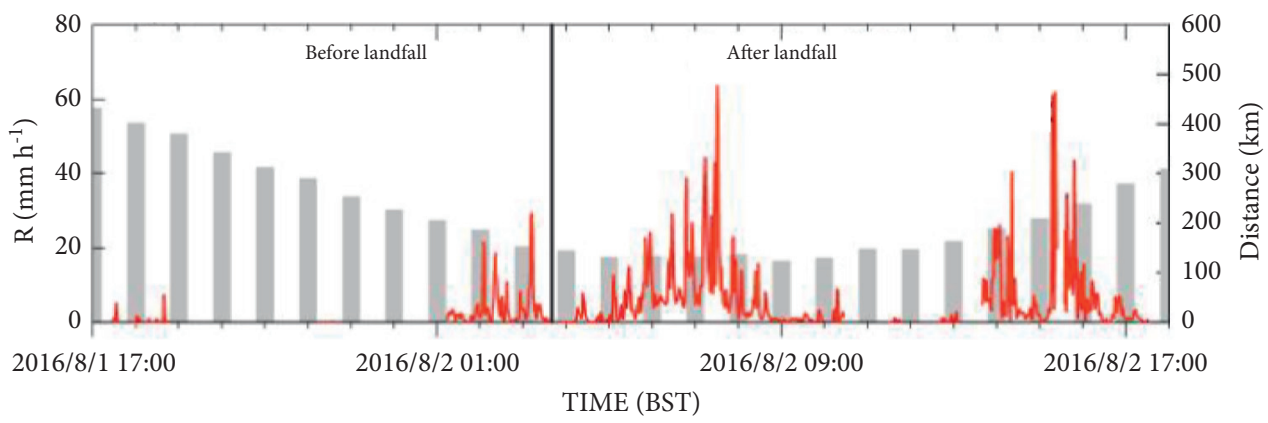

Distance

- R

(b)

Figure 5: Time evolutions of (a) logarithmic raindrop concentration $\operatorname{lgND}\left(\mathrm{mm}^{-1} \mathrm{~m}^{-3}\right)$ and (b) rain rate $R(\mathrm{~mm} \mathrm{~h})$ and distance $(\mathrm{km})$ from the TC center to the Longmen.

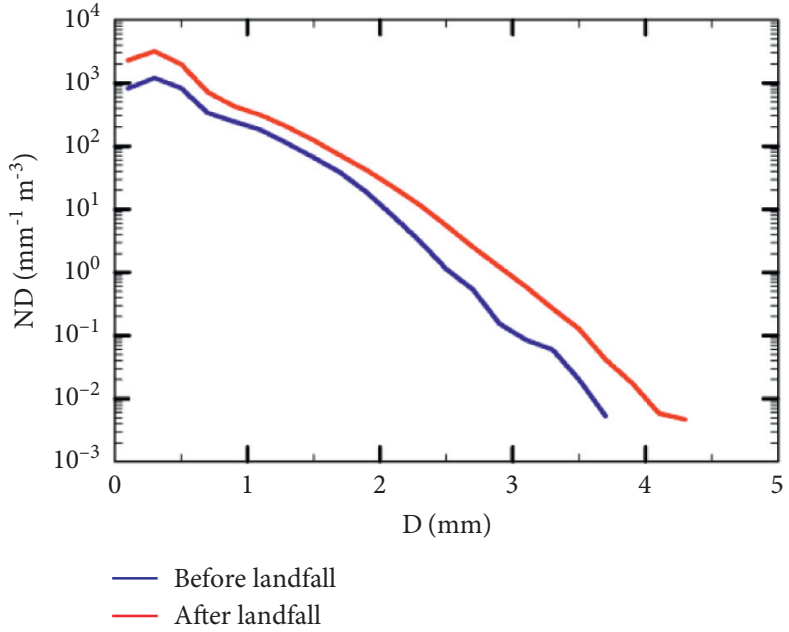

(a)

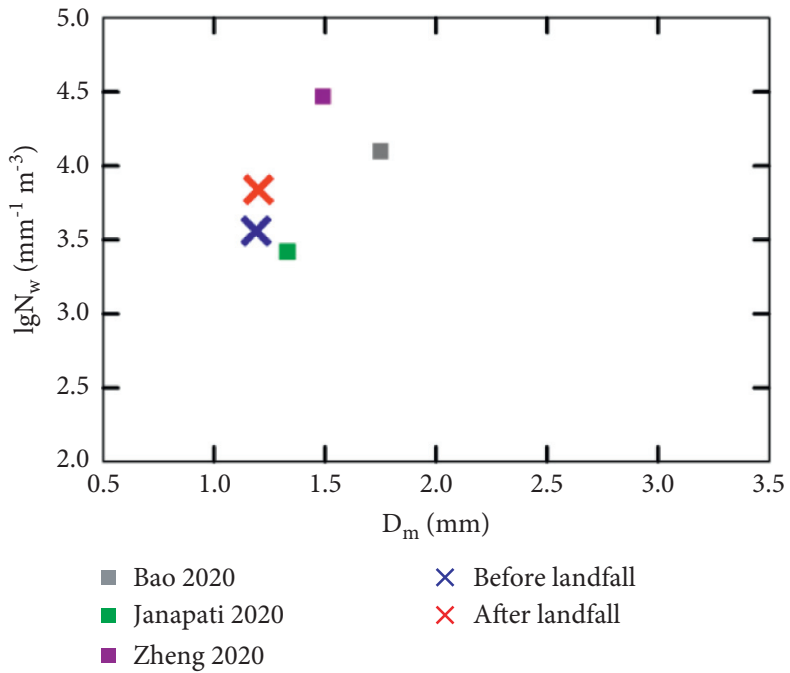

(b)

FIgURE 6: Continued. 


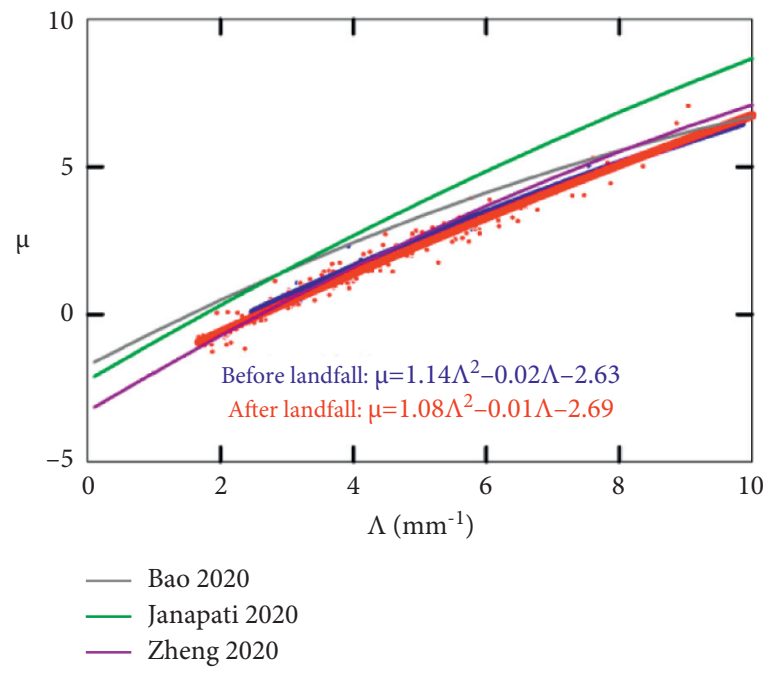

(c)

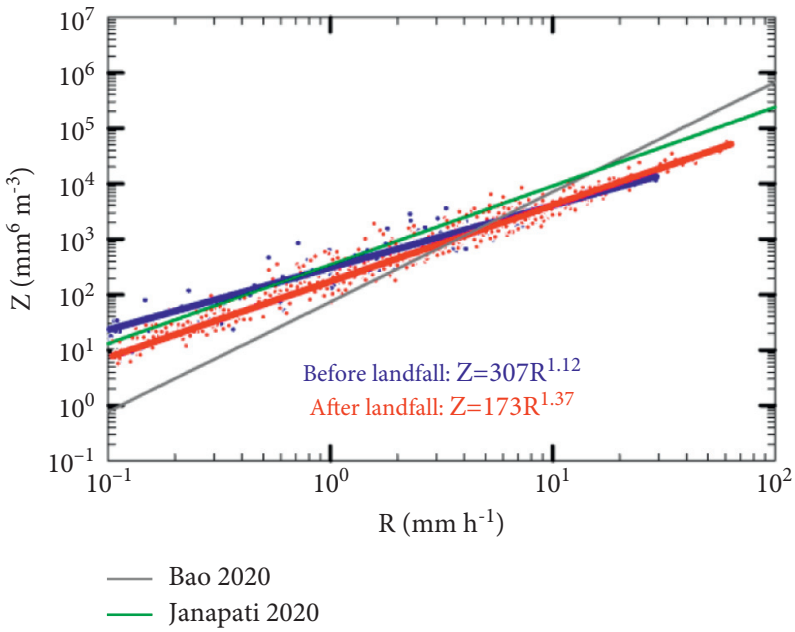

(d)

Figure 6: (a) Average raindrop spectra, (b) the mean and standard deviation values of mass-weighted mean diameter $D_{m}$ (mm) and logarithmic normalized intercept parameter $\lg N_{w}\left(\mathrm{~mm}^{-1} \mathrm{~m}^{-3}\right)$, (c) the shape and slope $(\mu-\Lambda)$ relationship, and (d) the radar reflectivity and rain rate $(Z-R)$ relationship before landfall and after landfall. The colored squares are the mean values of $D_{m}(\mathrm{~mm})$ and $\lg N_{w}\left(\mathrm{~mm}^{-1} \mathrm{~m}^{-3}\right)$, and the colored lines are the $\mu-\lambda$ relationship and $Z-R$ relationships from Bao et al. [41], Janapati et al. [31], and Zheng et al. [42].

TABLE 1: Mean of rain rate $R\left(\mathrm{~mm} \mathrm{~h}^{-1}\right)$, radar reflectivity $Z(\mathrm{dBZ})$, mass-weighted mean diameter $D_{m}(\mathrm{~mm})$, logarithmic normalized intercept parameter $\lg N_{w}\left(\mathrm{~mm}^{-1} \mathrm{~m}^{-3}\right)$, and the maximum diameter $D_{\max }(\mathrm{mm})$ at different rain rate classes before and after landfall.

\begin{tabular}{|c|c|c|c|c|c|c|c|c|c|c|}
\hline \multirow[b]{2}{*}{ Segment } & \multirow[b]{2}{*}{ Parameters } & \multicolumn{9}{|c|}{ Rain rate classes $\left(\mathrm{mm} \mathrm{h}^{-1}\right)$} \\
\hline & & $\begin{array}{c}\text { All } \\
\text { classes }\end{array}$ & $0.1-1$ & $1-5$ & $5-10$ & $10-20$ & $20-30$ & $30-40$ & $40-50$ & $>50$ \\
\hline \multirow{6}{*}{$\begin{array}{l}\text { Before } \\
\text { landfall }\end{array}$} & Numbers & 186 & $77(41.40 \%)$ & $82(44.09 \%)$ & $15(8.06 \%)$ & $8(4.30 \%)$ & $4(2.15 \%)$ & - & - & - \\
\hline & $R$ & 2.91 & 0.40 & 2.38 & 6.87 & 13.79 & 25.58 & - & - & - \\
\hline & $\mathrm{Z}$ & 24.68 & 17.34 & 27.97 & 33.22 & 37.87 & 40.42 & - & - & - \\
\hline & $D_{m}$ & 1.19 & 1.03 & 1.27 & 1.31 & 1.47 & 1.44 & - & - & - \\
\hline & $\lg N_{w}$ & 3.56 & 3.27 & 3.64 & 4.05 & 4.12 & 4.41 & - & - & - \\
\hline & $D_{\max }$ & 4.1 & 4.1 & 3.9 & 2.3 & 2.1 & 1.5 & & & \\
\hline \multirow{6}{*}{$\begin{array}{l}\text { After } \\
\text { landfall }\end{array}$} & Numbers & 610 & $186(30.49 \%)$ & $191(31.31 \%)$ & $126(20.66 \%)$ & $65(10.66 \%)$ & $26(4.26 \%)$ & $7(1.15 \%)$ & $4(0.65 \%)$ & $5(0.82 \%)$ \\
\hline & $R$ & 6.12 & 0.45 & 2.56 & 6.96 & 14.72 & 24.02 & 34.64 & 42.49 & 58.74 \\
\hline & $Z$ & 28.06 & 17.49 & 27.83 & 33.98 & 38.14 & 41.05 & 43.89 & 44.23 & 46.72 \\
\hline & $D_{m}$ & 1.20 & 0.95 & 1.20 & 1.33 & 1.43 & 1.51 & 1.67 & 1.59 & 1.71 \\
\hline & $\lg N_{w}$ & 3.84 & 3.50 & 3.80 & 4.04 & 4.21 & 4.31 & 4.27 & 4.46 & 4.46 \\
\hline & $D_{\max }$ & 4.3 & 4.1 & 4.3 & 4.3 & 3.7 & 3.7 & 2.3 & 1.9 & 2.7 \\
\hline
\end{tabular}

The distribution of mass-weighted mean diameter $D_{m}$ and logarithmic normalized intercept parameter $\lg N_{w}$ at different rain rate classes is shown in Figure 7. In the period both before landfall and after landfall, the distribution of $D_{m}$ and $\lg N_{w}$ was concentrated and the value of $D_{m}$ and $\lg N_{w}$ almost increased with rain intensity (Figure 7). During the period before landfall, the $D_{m}$ was concentrated between $0.5 \mathrm{~mm}$ and $2.5 \mathrm{~mm}$ and $\lg N_{w}$ was concentrated between 1.9 and $4.5 \mathrm{~mm}^{-1} \mathrm{~m}^{-3}$ (Figure $7(\mathrm{a})$ ). The maximum and minimum values of $D_{m}$ were the drops of $R<1 \mathrm{~mm} \mathrm{~h}^{-1}$. The maximum value of $\lg N_{w}$ was the drop of $R \sim 20-30 \mathrm{~mm} \mathrm{~h}^{-1}$, while the minimum value of $\lg N_{w}$ was the drop of $R<1 \mathrm{~mm} \mathrm{~h}^{-1}$. Then during the period after landfall, the $D_{m}$ was concentrated between 0.5 and $2.1 \mathrm{~mm}$ and $\lg N_{w}$ was concentrated between 2.6 and $4.7 \mathrm{~mm}^{-1} \mathrm{~m}^{-3}$, which was more concentrated than that before landfall (Figure $7(\mathrm{~b})$ ). The maximum value of $D_{m}$ was the drop of $R \sim 5-10 \mathrm{~mm} \mathrm{~h}^{-1}$, while the minimum value of $D_{m}$ was the drop of $R<1 \mathrm{~mm} \mathrm{~h}^{-1}$. The maximum value of $\lg N_{w}$ was the drop of $R \sim 5-10 \mathrm{~mm} \mathrm{~h}^{-1}$, while the minimum value of $\lg N_{w}$ was the drop of $R<1 \mathrm{~mm} \mathrm{~h}^{-1}$. When $R<20 \mathrm{~mm} \mathrm{~h}^{-1}$, the mean value of $D_{m}\left(\lg N_{w}\right)$ was almost smaller (larger) than the period before landfall.

Figure 8 shows the average raindrop spectra of different rain rate $\left(\mathrm{mm} \mathrm{h}^{-1}\right)$ classes. During the period before landfall, the raindrops spectral width was narrower with rain intensity, while the maximum diameter $\left(D_{\max }\right)$ decreased with the rain intensity (Table 1$)$. The concentration of small drops $(<1 \mathrm{~mm})$ increased first and then decreased gradually with rain intensity. There were a few large drops with a concentration of $0.01-0.15 \mathrm{~mm}^{-1} \mathrm{~m}^{-3}$. Then during the period after landfall, the concentration of each size bin was almost higher than that before landfall in each rain rate class. The raindrops spectral width was wider first and then narrower gradually with rain intensity. There were a few large drops with a concentration of 

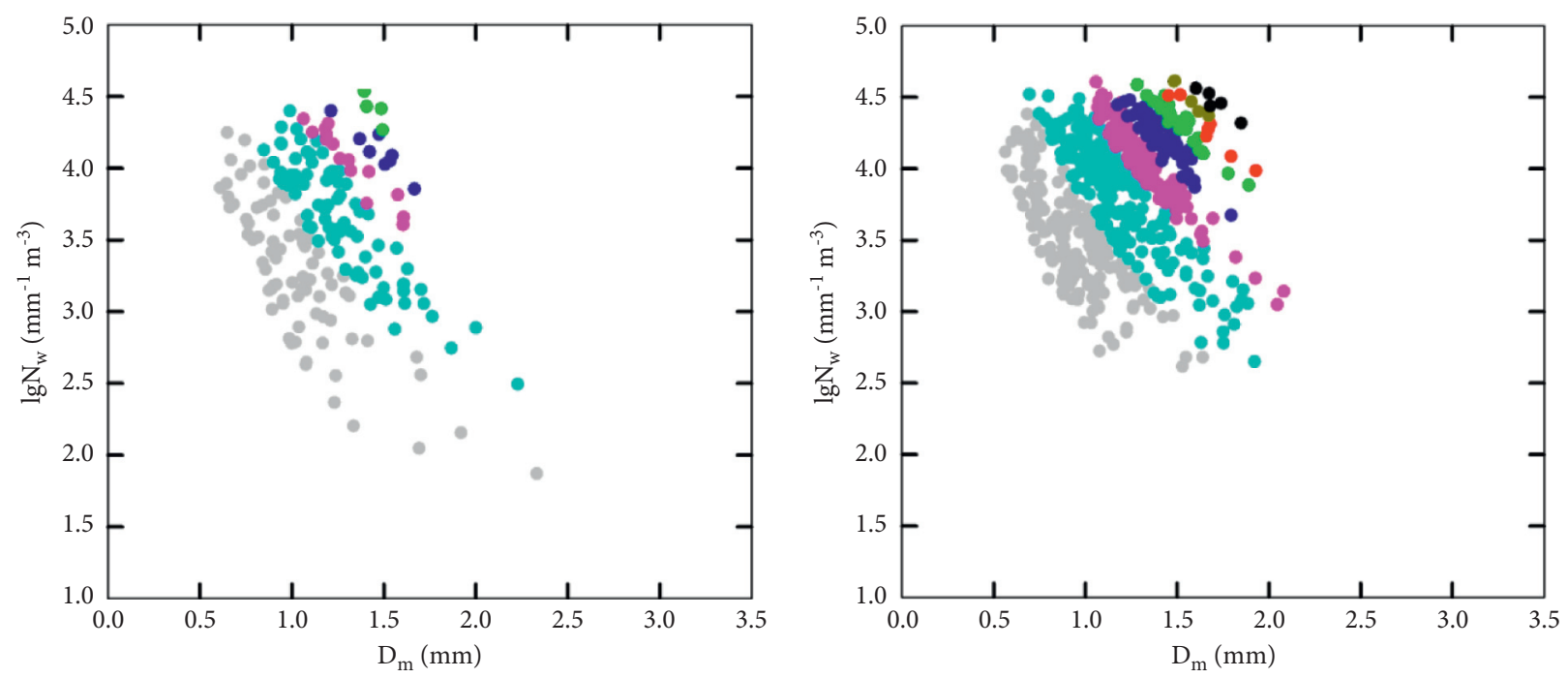

$\mathrm{R}\left(\mathrm{mm} \mathrm{h}^{-1}\right)$

- 0.1-1 20-30

- 1-5 $230-40$

- $5-10$

- $30-40$

- $10-20$

- $>50$

$\mathrm{R}\left(\mathrm{mm} \mathrm{h}^{-1}\right)$

- 0.1-1

- 20-30

- $1-5$

- $30-40$

- $5-10$

- $40-50$

- $10-20$

- $>50$

(a)

(b)

FIGURE 7: The distribution of mass-weighted mean diameter $D_{m}(\mathrm{~mm})$ and logarithmic normalized intercept parameter $\lg N_{w}\left(\mathrm{~mm}^{-1} \mathrm{~m}^{-3}\right)$ before landfall (a) and after landfall (b) at different rain rate classes. The colored dots represent different rain rate classes.

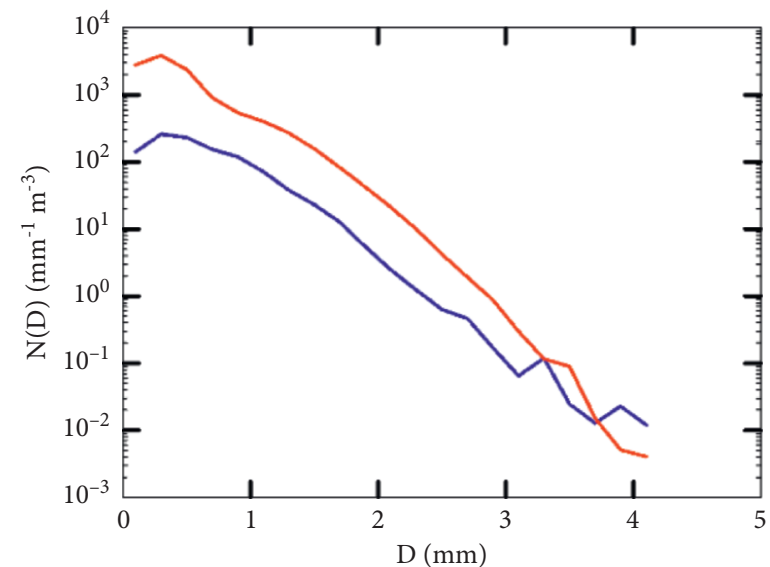

- Before landfall

- After landfall

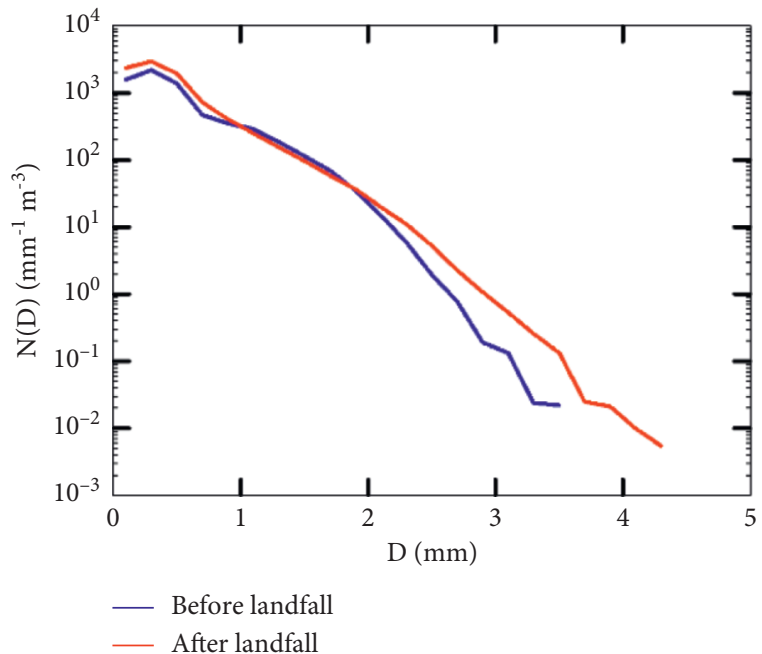

(b)

FIgURE 8: Continued. 


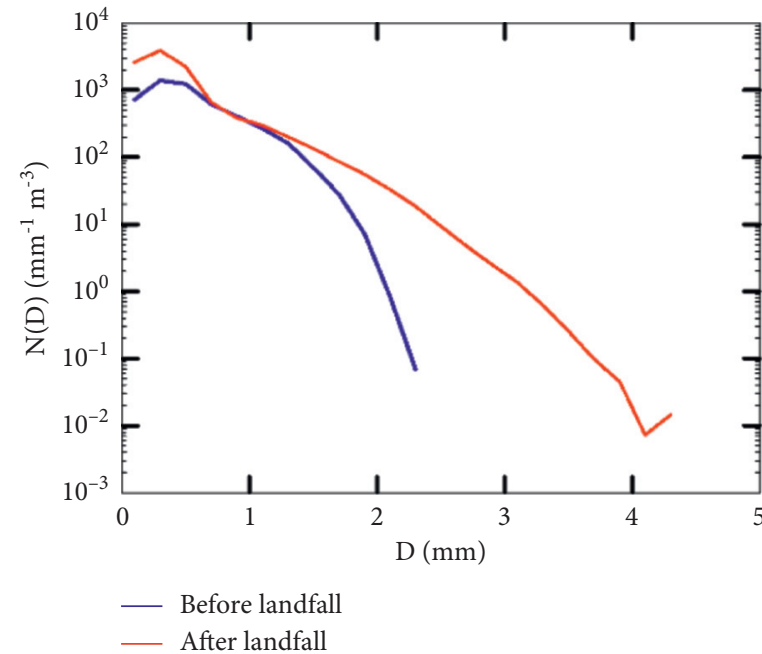

(c)

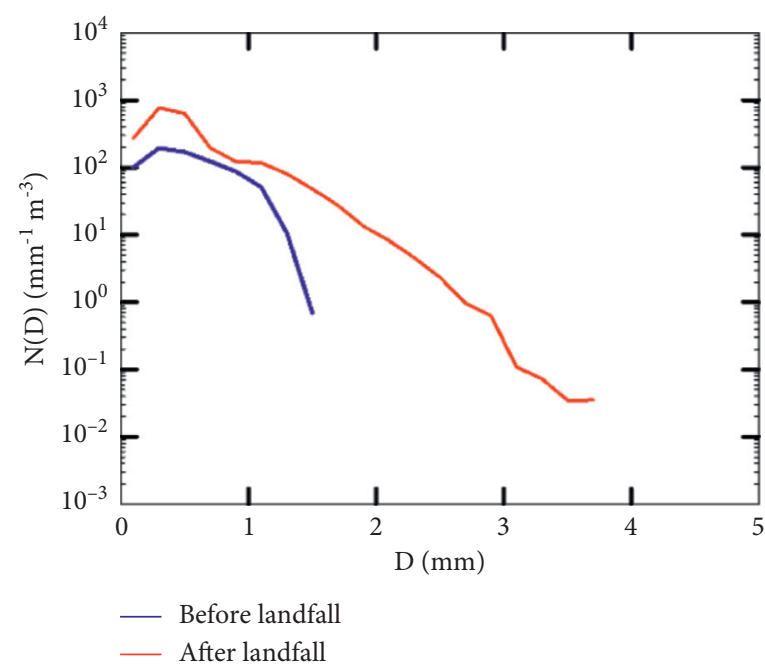

(e)

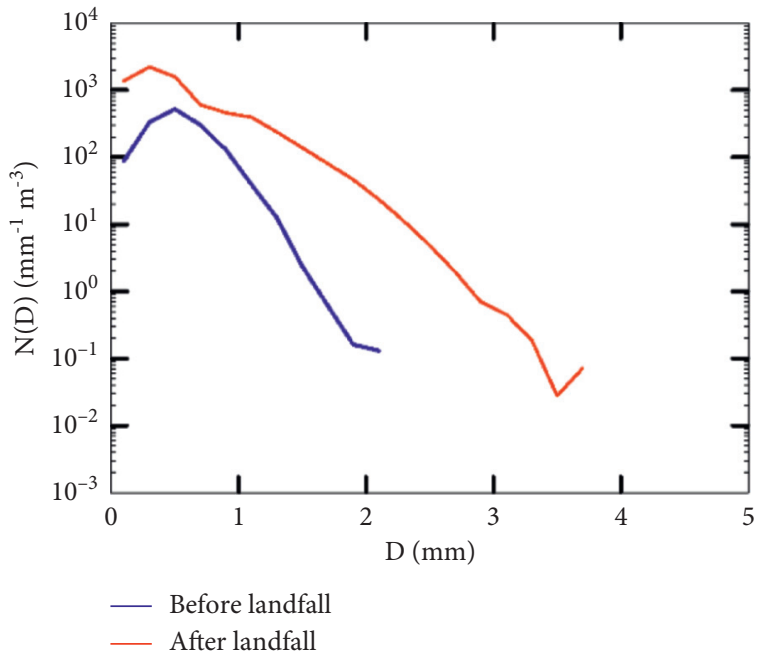

(d)

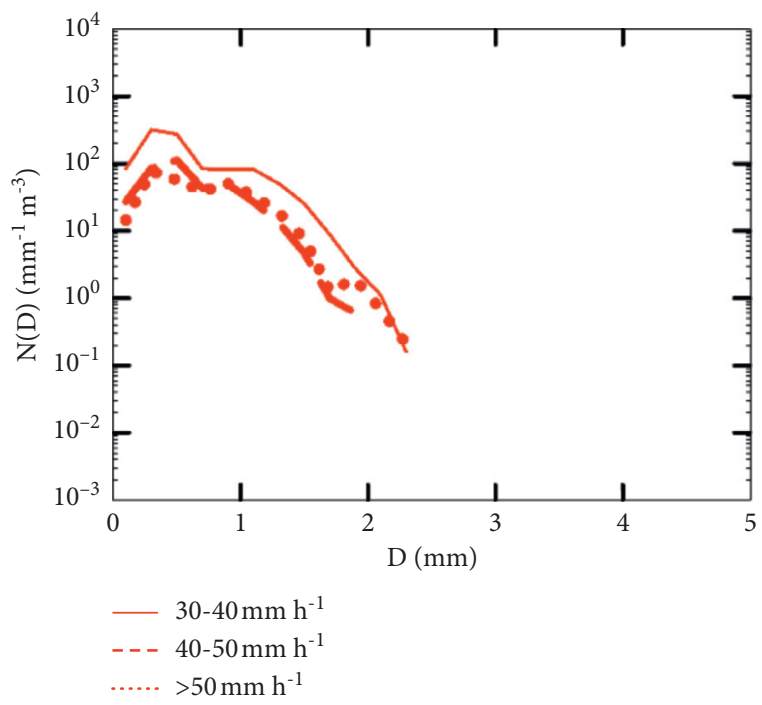

(f)

FiguRE 8: Raindrop spectra at different rain rate classes. (a) $0.1-1 \mathrm{~mm} \mathrm{~h}^{-1}$; (b) $1-5 \mathrm{~mm} \mathrm{~h}^{-1}$; (c) $5-10 \mathrm{~mm} \mathrm{~h}^{-1}$; (d) $10-20 \mathrm{~mm} \mathrm{~h}^{-1}$; (e) $20-30 \mathrm{~mm} \mathrm{~h}^{-1}$; (f) $>30 \mathrm{~mm} \mathrm{~h}^{-1}$.

$<1.5 \mathrm{~mm}^{-1} \mathrm{~m}^{-3}$. When $R \sim 0.1-1 \mathrm{~mm} \mathrm{~h}^{-1}$, the raindrop concentration difference between the period before landfall and after landfall was large, and particularly the small drop concentration difference was less than $3600 \mathrm{~mm}^{-1} \mathrm{~m}^{-3}$. When $R \sim 20-30 \mathrm{~mm} \mathrm{~h}^{-1}$, the raindrop concentration difference between the period before landfall and after landfall was small (less than $600 \mathrm{~mm}^{-1} \mathrm{~m}^{-3}$ ).

In the period both before landfall and after landfall, the maximum contribution to $R$ at each rain rate classes was midsize drops $(1-2 \mathrm{~mm})$, while the maximum contribution to $N_{t}$ at each rain rate classes was small drops (Figure 9). This indicated that the small and midsize drops $(<2 \mathrm{~mm})$ dominated typhoon precipitation in the period both before landfall and after landfall. From the period before landfall to the period after landfall, the contribution of midsize drops (1-2 mm) to $R$ decreased when $R \sim 1-30 \mathrm{~mm} \mathrm{~h}^{-1}$ and increased when $R>30 \mathrm{~mm} \mathrm{~h}^{-1}$, while the contribution of midsize drops $(2-3 \mathrm{~mm})$ to $R$ increased at each rain rate class. This also implied that the rain rate difference between the period before landfall and the period after landfall was mainly connected with midsize drops (1-3 mm).

\section{Summary}

During the passage of Typhoon Nida, the environmental condition was analyzed from NECP reanalysis data, sounding data at Heyuan station, and S-band polarimetric radar data at Guangzhou station, and the raindrop size distribution and raindrop shape relation characteristics were investigated based on the 2DVD. The DSD characteristics of different periods and rain rate classes were revealed. A summary of the conclusions is as follows: 


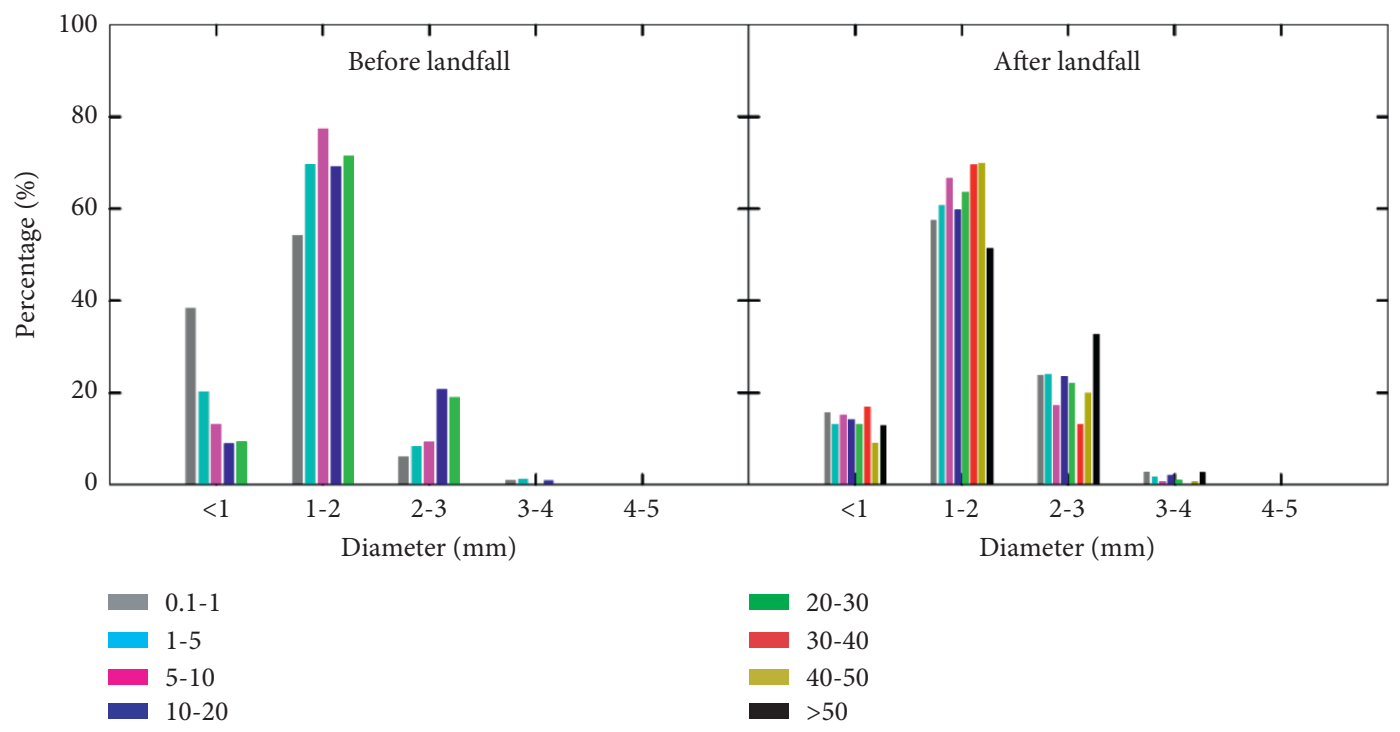

(a)

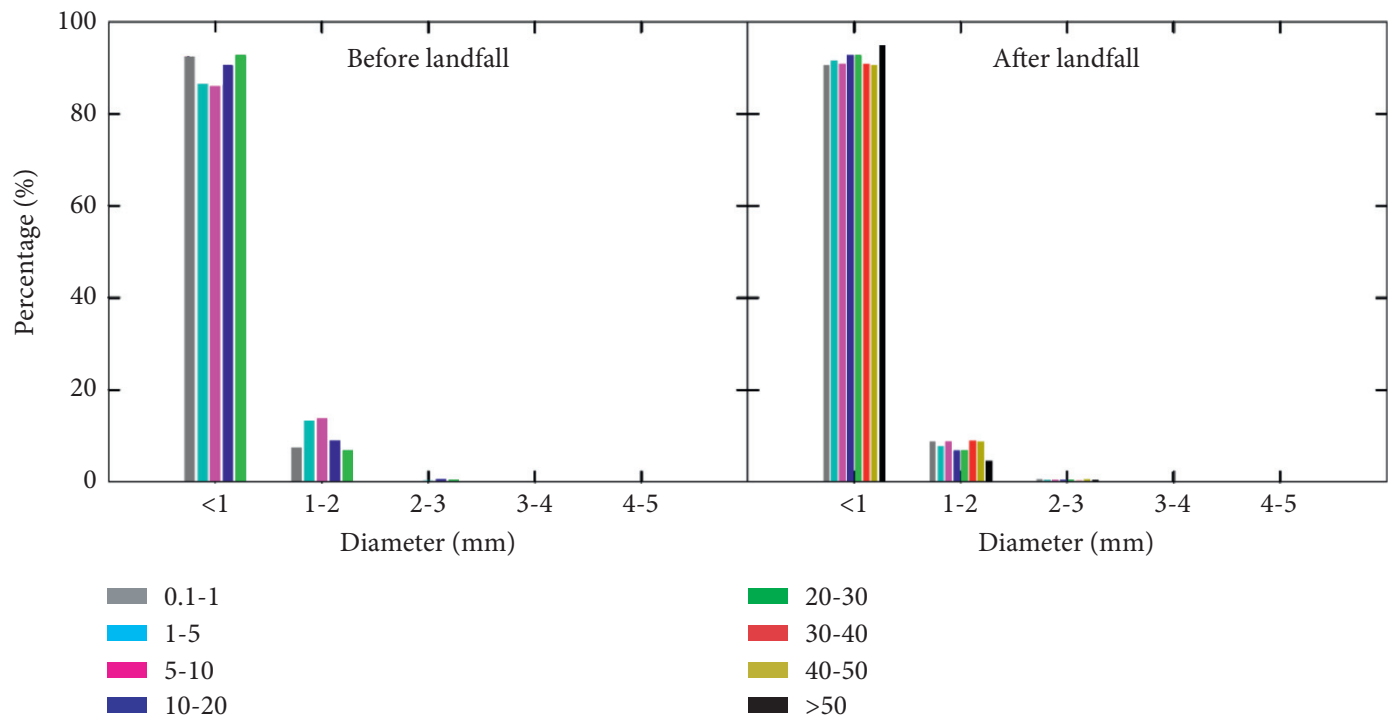

(b)

FIGURE 9: The contribution (\%) of particle size classes to rain rate $R\left(\mathrm{~mm} \mathrm{~h}^{-1}\right)$ and total raindrop number concentration $N_{t}\left(\mathrm{~m}^{-3}\right)$ at different rain rate classes.

(1) The Bay of Bengal and the South China Sea provided a sea of moisture to the formation of the typhoon precipitation. During the period before landfall, the environment with large CAPE, high TPW, and "horn" type (the atmosphere with upper-layer dry and lower-layer wet) strengthened the development of typhoon precipitation. Then during the period after landfall, the whole layer of atmosphere became wet and the CAPE was small.

(2) The DSD characteristics before landfall and after landfall were found to be different. The period after landfall exhibited higher concentrations of each size bin (particularly small drops) and wider raindrop spectral width than the period before landfall did. Compared with the period before landfall, the period after landfall had a high $D_{m}$ that was smaller than those of other TCs from the same ocean (the Pacific). The relationship between the radar reflectivity factor and the rain rate $(Z-R)$ was $Z=307 \mathrm{R}^{1.12}$ before landfall and $Z=173 \mathrm{R}^{1.37}$ after landfall. Moreover, there were some similar characteristics between the period before landfall and after landfall. In the period both before landfall and after landfall, the typhoon precipitation was mainly dominated by the midsize drops $(1-2 \mathrm{~mm})$. The shape and slope $(\mu-\Lambda)$ relationship were similar before landfall and after landfall, which were different from those of other TCs from the same ocean (the Pacific).

(3) The DSD characteristics in different rain rate classes before landfall and after landfall were also quite 
distinct. The precipitation particles mainly consist of the drops of $R<10 \mathrm{~mm} \mathrm{~h}^{-1}$ before landfall, while the precipitation particles mainly consist of the drops of $R<20 \mathrm{~mm} \mathrm{~h}^{-1}$ after landfall. In the period both before landfall and after landfall, the distribution of $D_{m}$ and $\lg N_{w}$ was concentrated and the value of $D_{m}$ and $\lg N_{w}$ almost increased with rain intensity. The rain rate difference between the period before landfall and the period after landfall was mainly connected with midsize drops.

In this study, even though the observations before landfall and after landfall were both from the outer rainbands of the TC, the DSD characteristics before landfall and after landfall differed considerably. Thus, the DSDs of TCs before and after landfall over southern China warrant further investigation, and this future research has important implications for the improvement of microphysical parameterization schemes during the simulation of TCs.

\section{Data Availability}

The 2DVD data used in this study were collected from the Longmen Field Experiment Base for Cloud Physics, China Meteorological Administration. The data are available upon request to the corresponding author at xiaoh@gd121.cn.

\section{Conflicts of Interest}

The authors declare no conflicts of interest.

\section{Acknowledgments}

The authors thank Yue Qian for translating the manuscript. This research was jointly supported by the Science and Technology Planning Project of Guangdong Province, China (2017B020244002), the National Natural Science Foundation of China (41975138, 41705120, 42075086, and 42005062), the Fundamental Research Funds for the Guangzhou Science and Technology Plan Project (201903010036), the Guangdong Basic and Applied Basic Research Foundation (2021A1515011415), and the Natural Science Foundation of Guangdong Province, China (2019A1515010814).

\section{References}

[1] N. V. P. Kirankumar, T. N. Rao, B. Radhakrishna, and D. N. Rao, "Statistical characteristics of raindrop size distribution in southwest monsoon season," Journal of Applied Meteorology and Climatology, vol. 47, no. 2, pp. 576-590, 2008.

[2] W. K. Tao, J. Simpson, D. Baker et al., "Microphysics, radiation and surface processes in the goddard cumulus ensemble (GCE) model," Meteorology \& Atmospheric Physics, vol. 82, no. 1, pp. 1-4, 2003.

[3] D. Rosenfeld and C. W. Ulbrich, "Cloud microphysical properties, processes, and rainfall estimation opportunities," Meteorological Monographs, vol. 30, no. 52, p. 237, 2003.
[4] V. N. Bringi, V. Chandrasekar, J. Hubbert, E. Gorgucci, W. L. Randeu, and M. Schoenhuber, "Raindrop size distribution in different climatic regimes from disdrometer and dual-polarized radar analysis," Journal of the Atmospheric Sciences, vol. 60, no. 2, pp. 354-365, 2003.

[5] S.-H. Suh, C.-H. You, and D.-I. Lee, "Climatological characteristics of raindrop size distributions in Busan, Republic of Korea," Hydrology and Earth System Sciences, vol. 20, no. 1, pp. 193-207, 2016.

[6] M. Thurai, V. N. Bringi, L. D. Carey, P. Gatlin, E. Schultz, and W. A. Petersen, "Estimating the accuracy of polarimetric radar-based retrievals of drop-size distribution parameters and rain rate: an application of error variance separation using radar-derived spatial correlations," Journal of Hydrometeorology, vol. 13, no. 3, pp. 1066-1079, 2012.

[7] G. Zhang, J. Vivekanandan, and E. Brandes, "A method for estimating rain rate and drop size distribution from polarimetric radar measurements," IEEE Transactions on Geoscience and Remote Sensing, vol. 39, no. 4, pp. 830-841, 2001.

[8] K. Friedrich, E. A. Kalina, F. J. Masters, and C. R. Lopez, "Drop-size distributions in thunderstorms measured by optical disdrometers during VORTEX2," Monthly Weather Review, vol. 141, no. 4, pp. 1182-1203, 2013.

[9] L. Luo, H. Xiao, H. L. Yang et al., "Raindrop size distribution and microphysical characteristics of a great rainstorm in 2016 in Beijing, China," Atmospheric Research, vol. 239, no. 1, Article ID 104895, 2020.

[10] Marzuki, W. L. Randeu, T. Kozu, T. Shimomai, H. Hashiguchi, and M. Schönhuber, "Raindrop axis ratios, fall velocities and size distribution over sumatra from $2 \mathrm{D}$-video disdrometer measurement," Atmospheric Research, vol. 119, no. 1, pp. 23-37, 2013.

[11] A. Tokay, P. G. Bashor, E. Habib, and T. Kasparis, "Raindrop size distribution measurements in tropical cyclones," Monthly Weather Review, vol. 136, no. 5, pp. 1669-1685, 2008.

[12] F. Roberto, C. Amaya, G. C. Miguel et al., "Vertical raindrop size distribution in Central Spain: a case study," Advances in Meteorology, vol. 2015, Article ID 647647, 9 pages, 2015.

[13] T. H. Raupach and A. Berne, "Correction of raindrop size distributions measured by parsivel disdrometers, using a twodimensional video disdrometer as a reference," Atmospheric Measurement Techniques, vol. 8, no. 1, pp. 343-365, 2015.

[14] A. Kruger and W. F. Krajewski, "Two-dimensional video disdrometer: a description," Journal of Atmospheric and Oceanic Technology, vol. 19, no. 5, pp. 602-617, 2002.

[15] X. Liu, Q. Wan, H. Wang et al., "Raindrop size distribution parameters retrieved from Guangzhou S-band polarimetric radar observations," Journal of Meteorological Research, vol. 32, no. 4, pp. 571-583, 2018.

[16] E. Adirosi, L. Baldini, and A. Tokay, "Rainfall and DSD parameters comparison between micro rain radar, two-dimensional video and parsivel 2 disdrometers, and S-band dual-polarization radar," Journal of Atmospheric and Oceanic Technology, vol. 37, no. 4, pp. 621-640, 2020.

[17] E. Gorgucci, V. Chandrasekar, V. N. Bringi, and G. Scarchilli, "Estimation of raindrop size distribution parameters from polarimetric radar measurements," Journal of the Atmospheric Sciences, vol. 59, no. 15, pp. 2373-2384, 2001.

[18] Y. Ding, Q. L. Wan, L. Yang et al., "Raindrop size distribution parameters retrieved from xinfeng c-band polarimetric radar observations," Journal of Tropical Meteorology, vol. 26, no. 3, pp. 275-286, 2020.

[19] M. J. Wang, K. Zhao, M. Xue et al., "Precipitation microphysics characteristics of a Typhoon Matmo (2014) rainband 
after landfall over eastern China based on polarimetric radar observations," Journal of Geophysical Research: Atmospheres, vol. 121, pp. 12415-12433, 2016.

[20] E. Yoshikawa, V. Chandrasekar, and T. Ushio, "Raindrop size distribution (DSD) retrieval for X-band dual-polarization radar," Journal of Atmospheric and Oceanic Technology, vol. 31, no. 2, pp. 387-403, 2014.

[21] K. Song, X. Liu, T. Gao, and B. He, "Raindrop size distribution retrieval using joint dual-frequency and dual-polarization microwave links," Advances in Meteorology, vol. 2019, Article ID 7251870, 11 pages, 2019.

[22] A. Zhang and Y. Fu, "Life cycle effects on the vertical structure of precipitation in east China measured by himawari- 8 and GPM DPR," Monthly Weather Review, vol. 146, no. 7, pp. 2183-2199, 2018.

[23] Y. L. Chen, W. B. Li, S. M. Chen, A. Q. Zhang, and Y. F. Fu, "Linkage between the vertical evolution of clouds and droplet growth modes as seen from FY-4A AGRI and GPM DPR," Geophysical Research Letters, vol. 47, no. 15, 2020.

[24] J. Janapati, B. K. Seela, P. L. Lin, M. T. Lee, and E. Joseph, "Microphysical features of typhoon and non-typhoon rainfall observed in Taiwan, an island in the northwest Pacific," Hydrology and Earth System Sciences Discussions, vol. 25, no. 7, pp. 4025-4040, 2020.

[25] L. Wen, K. Zhao, G. Chen et al., "Drop size distribution characteristics of seven typhoons in China," Journal of Geophysical Research Atmospheres, vol. 123, no. 12, pp. 65296548, 2018.

[26] W. Y. Chang, T. C. C. Wang, and P. L. Lin, "Characteristics of the raindrop size distribution and drop shape relation in typhoon systems in the western pacific from the $2 \mathrm{D}$ video disdrometer and NCU C-band polarimetric radar," Journal of Atmospheric and Oceanic Technology, vol. 26, no. 10, pp. 1973-1993, 2009.

[27] B. Radhakrishna and T. N. Rao, "Differences in cyclonic raindrop size distribution from southwest to northeast monsoon season and from that of noncyclonic rain," Journal of Geophysical Research Atmospheres, vol. 115, no. D16, 2010.

[28] A. Deo and K. J. E. Walsh, "Contrasting tropical cyclone and non-tropical cyclone related rainfall drop size distribution at Darwin, Australia," Atmospheric Research, vol. 181, pp. 81-94, 2016.

[29] R. A. Houze, "Clouds in tropical cyclones," Monthly Weather Review, vol. 138, no. 2, pp. 293-344, 2010.

[30] R. A. Houze, F. D. Marks, and R. A. Black, "Dual-aircraft investigation of the inner core of Hurricane Norbert. part II: mesoscale distribution of ice particles," Journal of the Atmospheric Sciences, vol. 49, no. 11, pp. 943-963, 1992.

[31] J. Janapati, B. K. Seela, P.-L. Lin et al., "Raindrop size distribution characteristics of Indian and pacific ocean tropical cyclones observed at India and Taiwan sites," Journal of the Meteorological Society of Japan. Ser. II, vol. 98, no. 2, pp. 299-317, 2020.

[32] B. J. Chen, Y. Wang, and J. Ming, "Microphysical characteristics of the raindrop size distribution in Typhoon Morakot (2009)," Journal of Tropical Meteorology, vol. 18, no. 2, pp. 162-171, 2012.

[33] L. Feng, S. Hu, X. Liu et al., "Precipitation microphysical characteristics of Typhoon Mangkhut in southern China using 2D video disdrometers," Atmosphere, vol. 11, no. 9, p. $975,2020$.

[34] J. Janapati, B. K. Seela, and M. Venkatrami Reddy, “A study on raindrop size distribution variability in before and after landfall precipitations of tropical cyclones observed over southern India," Journal of Atmospheric and Solar-Terrestrial Physics, vol. 159, pp. 23-40, 2017.

[35] F. D. Marks, D. Atlas, and P. T. Willis, "Probability-matched reflectivity-rainfall relations for a hurricane from aircraft observations," Journal of Applied Meteorology, vol. 32, no. 6, pp. 1134-1141, 1993.

[36] A. Tokay, W. A. Petersen, P. Gatlin, and M. Wingo, "Comparison of raindrop size distribution measurements by collocated disdrometers," Journal of Atmospheric and Oceanic Technology, vol. 30, no. 8, pp. 1672-1690, 2013.

[37] L. Feng, F. Xia, Q. L. Wang et al., "Characteristics of the raindrop size distribution in two squall lines measured by two-dimensional video disdrometer at Guangdong," Journal of Tropical Meteorology, vol. 35, no. 6, pp. 812-821, 2019, in Chinese.

[38] D. Wu, K. Zhao, M. R. Kumjian et al., "Kinematics and microphysics of convection in the outer rainband of Typhoon Nida (2016) revealed by polarimetric radar," Monthly Weather Review, vol. 146, no. 7, pp. 2147-2159, 2018.

[39] X. Feng, J. Sun, D. Yang, B. Yin, G. Gao, and W. Wan, "Effect of drag coefficient parameterizations on air-sea coupled simulations: a case study for Typhoons Haima and Nida in 2016," Journal of Atmospheric and Oceanic Technology, vol. 38, no. 5, pp. 977-993, 2021.

[40] O. P. Prat and B. R. Nelson, "Mapping the world's tropical cyclone rainfall contribution over land using the TRMM multi-satellite precipitation analysis," Water Resources Research, vol. 49, no. 11, pp. 7236-7254, 2013.

[41] X. Bao, L. Wu, S. Zhang, H. Yuan, and H. Wang, "A comparison of convective raindrop size distributions in the eyewall and spiral rainbands of Typhoon Lekima (2019)," Geophysical Research Letters, vol. 47, no. 23, 2020.

[42] H. Zheng, Y. Zhang, L. Zhang, H. Lei, and Z. Wu, "Precipitation microphysical processes in the inner rainband of tropical cyclone kajiki (2019) over the South China sea revealed by polarimetric radar," Advances in Atmospheric Sciences, vol. 38, no. 1, pp. 65-80, 2020.

[43] G. Zhang, J. Vivekanandan, E. A. Brandes, R. Meneghini, and T. Kozu, "The shape-slope relation in observed gamma raindrop size distributions: statistical error or useful information?" Journal of Atmospheric and Oceanic Technology, vol. 20, no. 8, pp. 1106-1119, 2003.

[44] A. D. Ochou, E. P. Zahiri, B. Bamba, and M. Koffi, "Understanding the variability of Z-R relationships caused by natural variations in raindrop size distributions (DSD): implication of drop size and number," Atmospheric and Climate Sciences, vol. 1, no. 3, 2011.

[45] H. R. Pruppacher and J. D. Klett, Microphysics of Clouds and Precipitation, Kluwer Academic Publishers, Dordrecht, Netherlands, 2010.

[46] Y. Fujiyoshi, T. Endoh, T. Yamada, K. Tsuboki, Y. Tachibana, and G. Wakahama, "Determination of a Z-R relationship for snowfall using a radar and high sensitivity snow gauges," Journal of Applied Meteorology, vol. 29, no. 2, pp. 147-152, 1990.

[47] H. Y. Wang, Z. H. Wang, T. X. Yang et al., "Effects of transmitting antenna elevation on bistatic polarization radar system ability detecting rotatory spheroidal raindrops," Plateau Meteorology, vol. 32, no. 4, pp. 1165-1173, 2013, in Chinese. 